\title{
Conventional and Unconventional Monetary Policy
}

\author{
Vasco Cúrdia and Michael Woodford
}

\begin{abstract}
The authors extend a standard New Keynesian model to incorporate heterogeneity in spending opportunities and two sources of (potentially time-varying) credit spreads and to allow a role for the central bank's balance sheet in equilibrium determination. They use the model to investigate the implications of imperfect financial intermediation for familiar monetary policy prescriptions, and to consider additional dimensions of central bank policy—variations in the size and composition of the central bank's balance sheet and payment of interest on reserves-alongside the traditional question of the proper choice of setting an operating target for an overnight policy rate. The authors also give particular attention to the special problems that arise when the policy rate reaches the zero lower bound. They show that it is possible within a single unified framework to identify the criteria for policy to be optimal along each dimension. The suggested policy prescriptions apply equally well when financial markets work efficiently as when they are substantially disrupted and interest rate policy is constrained by the zero lower bound. (JEL E44, E52)
\end{abstract}

Federal Reserve Bank of St. Louis Review, July/August 2010, 92(4), pp. 229-64.

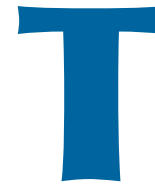

he recent global financial crisis has confronted central banks with a number of questions beyond the scope of many conventional accounts of the theory of monetary policy. For example, do projections of the paths of inflation and of aggregate real activity under some contemplated path for policy provide a sufficient basis for monetary policy decisions, or must financial conditions be given independent weight in such deliberations? That the Fed began aggressively cutting its target for the federal funds rate in late 2007 and early 2008, while inflation was arguably increasing and real GDP was not yet known to be contracting-and has nonetheless often been criticized as responding too slowly in this periodsuggests that familiar prescriptions that focus on inflation and real GDP alone, such as the Taylor (1993) rule or common accounts of "flexible inflation targeting" (Svensson, 1997), may be inadequate to circumstances of the kind recently faced. ${ }^{1}$ As a further, more-specific question, how should a central bank's interest rate policy be affected by the observation that other key interest rates no longer co-move with the policy rate (the federal funds rate in the case of the United States) in the way they typically have in the past? The dramatically different behavior of the LIBOR-OIS spread, shown in Figure 1, since August 2007, has drawn particular comment. Indeed, John Taylor

1 See Mishkin (2008) for discussion of some of the considerations behind the Fed's relatively aggressive rate cuts in the early part of the crisis.

Vasco Cúrdia is an economist at the Federal Reserve Bank of New York. Michael Woodford is a professor in the department of economics at Columbia University. The authors thank Michele Boldrin, Gauti Eggertsson, Marvin Goodfriend, Jamie McAndrews, John Taylor, and Kazuo Ueda for helpful discussions; Neil Mehrotra, Ging Cee Ng, and Luminita Stevens for research assistance; and the National Science Foundation for research support of the second author.

(C) 2010, The Federal Reserve Bank of St. Louis. The views expressed in this article are those of the author(s) and do not necessarily reflect the views of the Federal Reserve System, the Board of Governors, the Federal Reserve Bank of New York or the regional Federal Reserve Banks. Articles may be reprinted, reproduced, published, distributed, displayed, and transmitted in their entirety if copyright notice, author name(s), and full citation are included. Abstracts, synopses, and other derivative works may be made only with prior written permission of the Federal Reserve Bank of St. Louis. 


\section{Figure 1}

\section{Spread Between the U.S. Dollar LIBOR Rate and the Corresponding OIS Rate}

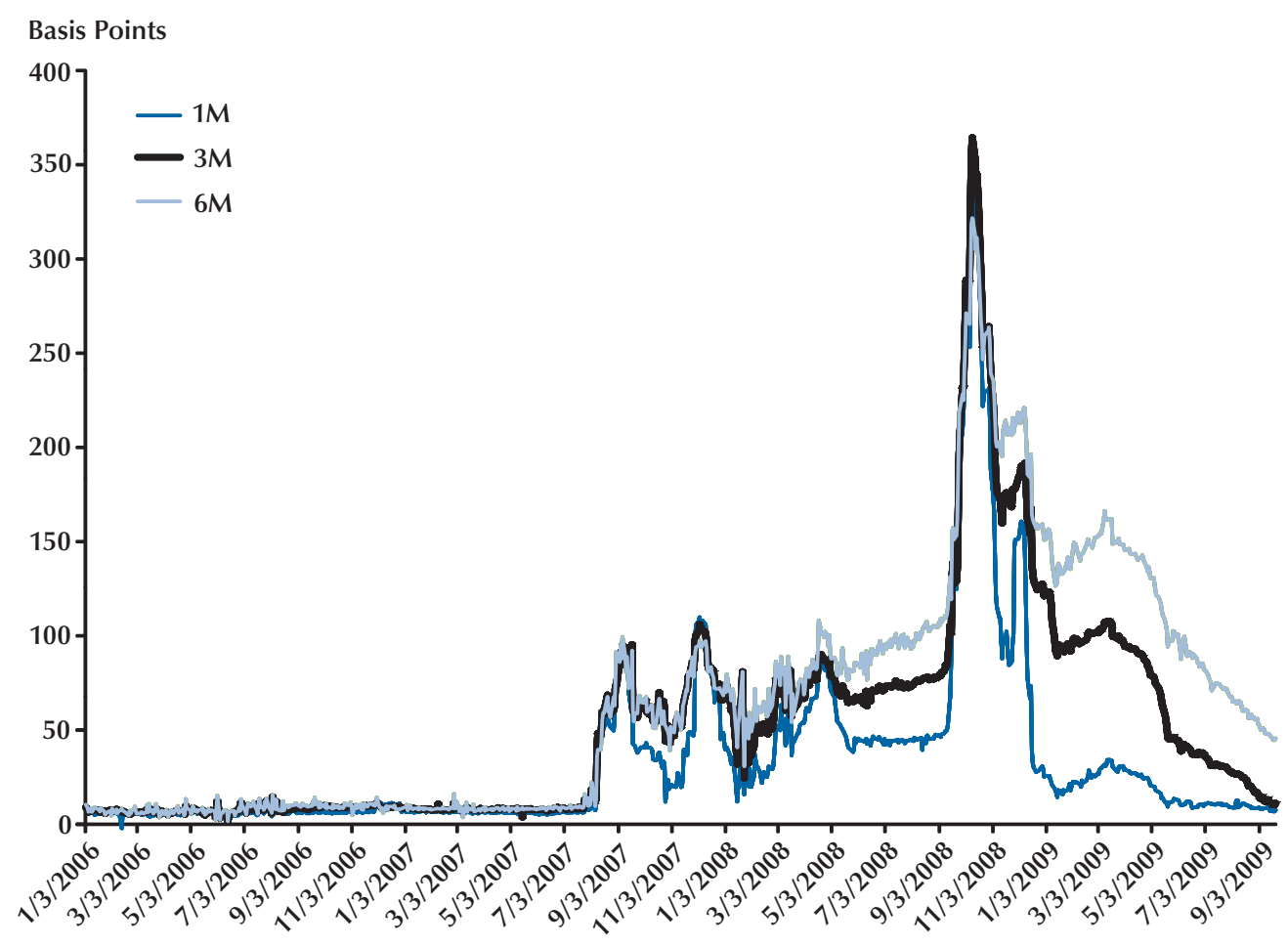

SOURCE: Bloomberg.

himself (Taylor, 2008) has suggested that movements in this spread should be taken into account in an extension of his famous rule.

In addition to such new questions about traditional interest rate policy, the very focus on interest rate policy as the central question about monetary policy has been called into question. The explosive growth of base money in the United States since September 2008 (shown in Figure 2) has led many commentators to suggest that the main instrument of U.S. monetary policy has changed from an interest rate policy to one often described as "quantitative easing." Does it make sense to regard the supply of bank reserves (or perhaps the monetary base) as an alternative or superior operating target for monetary policy? Does this (as some would argue) become the only important monetary policy decision once the overnight rate (the federal funds rate) has reached the zero lower bound, as it effectively has in the United States since December 2008 (Figure 3)?

And now that the Federal Reserve has legal authorization to pay interest on reserves (under the Emergency Economic Stabilization Act of 2008), how should this additional potential dimension of policy be used?

The past two years have also seen dramatic developments in the composition of the asset side of the Fed's balance sheet (Figure 4). Whereas the Fed had largely held Treasury securities on its balance sheet before the fall of 2007, other kinds of assets-including both a variety of new "liquidity facilities" and new programs under which the Fed has essentially become a direct lender to certain sectors of the economy-have rapidly grown in importance. How to manage these programs has 


\section{Figure 2}

\section{Liabilities of the Federal Reserve}

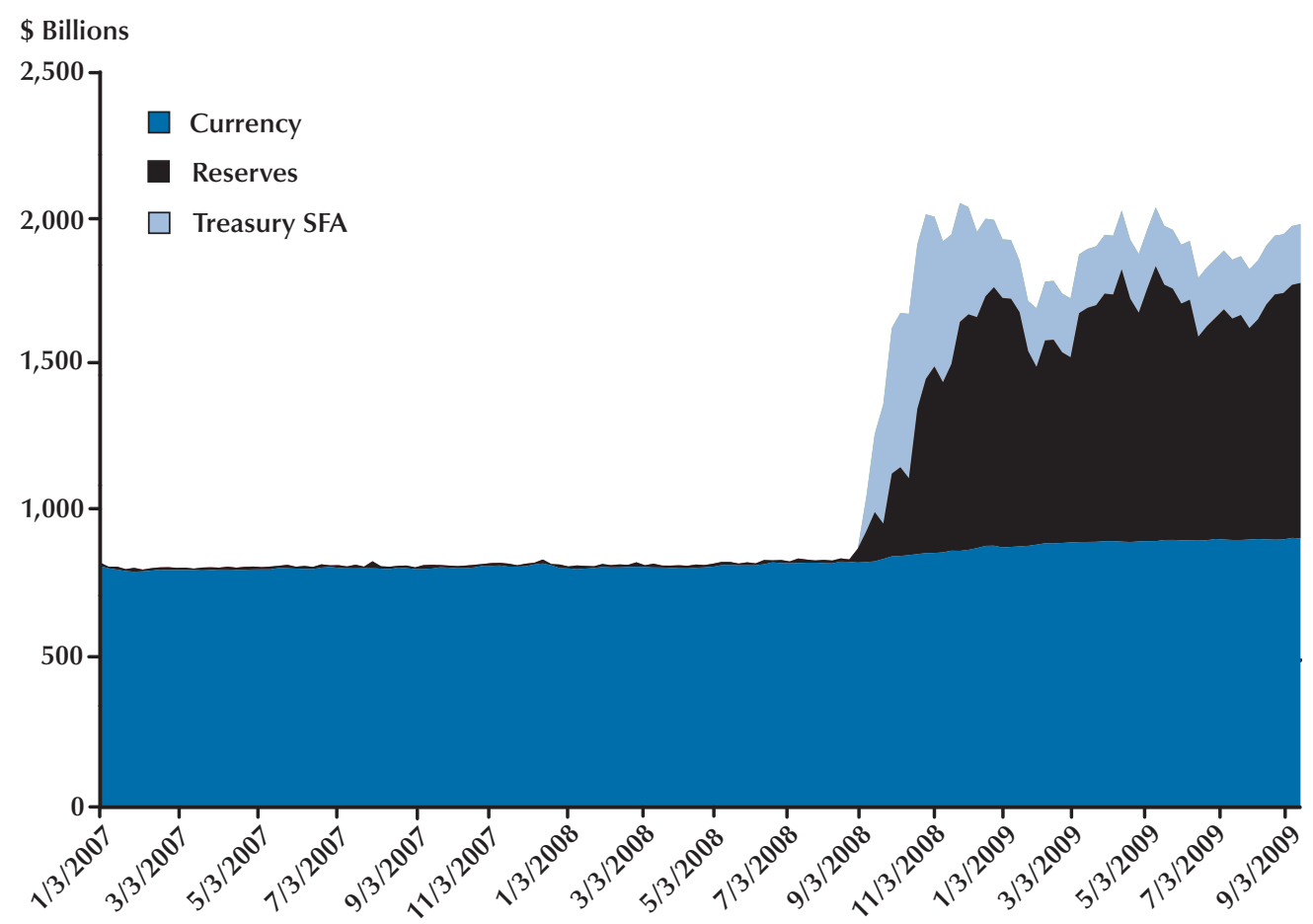

SOURCE: Federal Reserve Board.

occupied much of the attention of policymakers recently. How should one think about the aims of these programs and the relation of this new component of Fed policy to traditional interest rate policy? Is Federal Reserve credit policy a substitute for interest rate policy, or should it have different goals from those of interest rate policy?

These are clearly questions that a theory of monetary policy adequate to our present circumstances must address. Yet, not only these questions received relatively little attention until recently, but the very models commonly used to evaluate the effects of alternative prescriptions for monetary policy have little to say about them. Many New Keynesian (NK) models abstract entirely from the role of financial intermediation in the economy (by assuming a representative household) or assume perfect risk-sharing (to facilitate aggregation), so that the consequences of financial disruptions cannot be addressed. Many models include only a single interest rate (or only a single interest rate of a given maturity, with long rates tied to short rates through a no-arbitrage condition) and hence cannot say anything about the proper response to changes in spreads. And many models abstract entirely from the balance sheet of the central bank, so that questions about the additional dimensions of policy resulting from the possibility of varying the size and composition of the balance sheet cannot be addressed. ${ }^{2}$

2 In a representative-household model, abstraction from the role of the central bank's balance sheet in equilibrium determination is relatively innocuous; in particular, Eggertsson and Woodford (2003) show that introducing both a large range of possible choices about the composition of the balance sheet and transactions frictions that accord a special role to central bank liabilities need not imply any additional channels through which monetary policy can affect the economy when the zero lower bound is reached. However, we wish to reconsider this question in a framework where financial intermediation is both essential and costly. 


\section{Figure 3}

\section{FOMC Operating Target for the Federal Funds Rate}

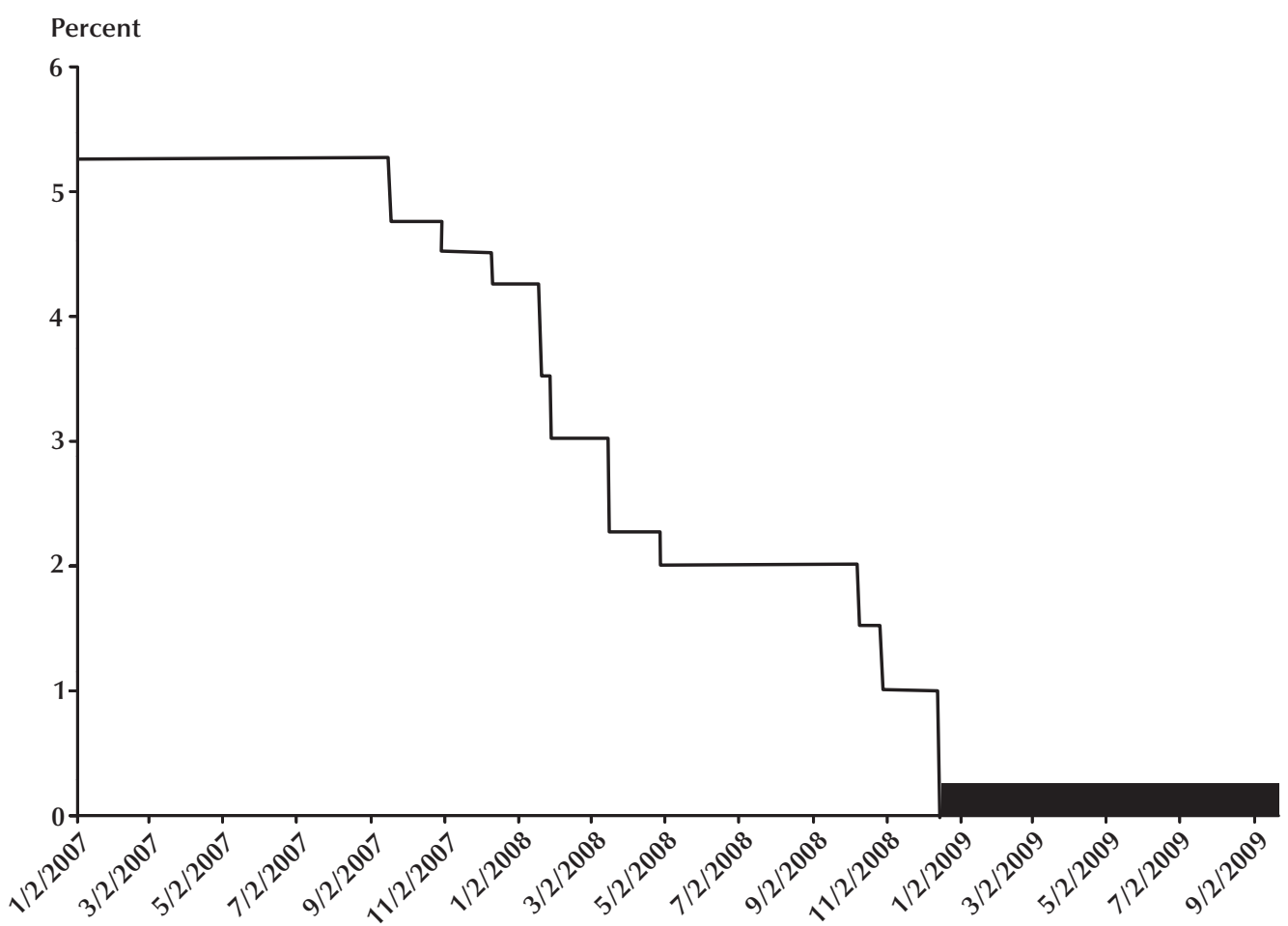

NOTE: Beginning with December 2008, the target rate is replaced with a target bank of 0 to 25 basis points.

SOURCE: Federal Reserve Board.

The aim of the research summarized here ${ }^{3}$ is to show how such issues can be addressed in a dynamic stochastic general equilibrium (DSGE) framework. We extend a basic NK model in directions that are crucial for analysis of the questions just posed: We introduce (i) nontrivial heterogeneity in spending opportunities, so that financial intermediation matters for the allocation of resources; (ii) imperfections in private financial intermediation and the possibility of disruptions to the efficiency of intermediation for reasons taken here as exogenous; and (iii) additional dimensions of central bank policy, by explicitly considering the role of the central bank's balance sheet in equilibrium determination and by allow-

3 This paper summarizes results that are explained in greater detail in Cúrdia and Woodford (2009a, 2009b, 2010). ing central bank liabilities to supply transactions services. Unlike some other recent approaches to the introduction of financial intermediation into NK DSGE models ${ }^{4}$ —which arguably include some features that allow for greater quantitative realism-our aim has been to develop a model that departs from a standard (representativehousehold) model in only the most minimal ways necessary to address the issues raised above. In this way, we can nest the standard (and extensively studied) model as a special case of our model so that the sources of our results and the precise significance of the new model elements introduced can be more clearly understood.

\footnotetext{
4 This has been a very active literature of late. See, for example, Christiano, Motto, and Rostagno (2007), Faia and Monacelli (2007), Gerali et al. (2008), and Gertler and Karadi (2009).
} 


\section{Figure 4}

\section{Assets of the Federal Reserve}

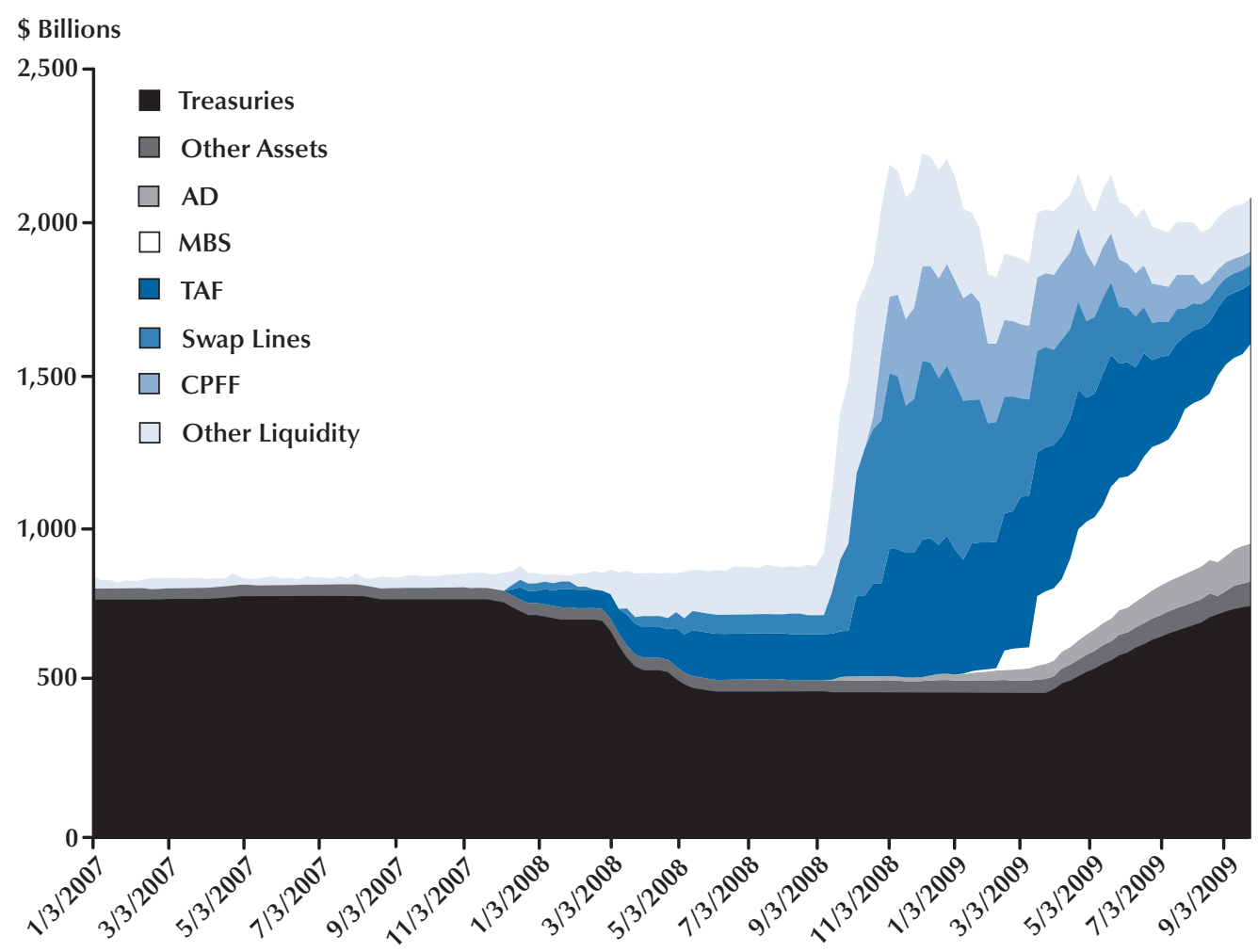

SOURCE: Federal Reserve Board.

\section{A MODEL WITH MULTIPLE DIMENSIONS OF MONETARY POLICY}

Here we sketch the key elements of our model, which extends the model introduced in Cúrdia and Woodford (2009a), to introduce the additional dimensions of policy associated with the central bank's balance sheet. (See this earlier paper, especially its technical appendix, for more details.) We stress the similarity between the model developed there and the basic NK model and show how the standard model is recovered as a special case of the extended model.

\subsection{Heterogeneity and the Allocative Consequences of Credit Spreads}

Our model is a relatively simple generalization of the basic NK model used by Goodfriend and King (1997), Clarida, Gali, and Gertler (1999), Woodford (2003), and others to analyze optimal monetary policy. The model is still highly stylized in many respects; for example, we abstract from the distinction between the household and firm sectors of the economy and instead treat all private expenditure as the expenditure of infinitely lived household-firms. Similarly, we abstract from the consequences of investment spending for the evolution of the economy's productive capacity, 


\section{Cúrdia and Woodford}

instead treating all private expenditure as if it were nondurable consumer expenditure (yielding immediate utility at a diminishing marginal rate).

We depart from the assumption of a representative household in the standard model by supposing that households differ in their preferences. Each household $i$ seeks to maximize a discounted intertemporal objective of the form

$$
\text { (1) } E_{0} \sum_{t=0}^{\infty} \beta^{t}\left[u^{\tau_{t}(i)}\left(c_{t}(i) ; \xi_{t}\right)-\int_{0}^{1} v^{\tau_{t}(i)}\left(h_{t}(j ; i) ; \xi_{t}\right) d j\right] \text {, }
$$

where $\tau(i) \in\{b, s\}$ indicates the household's "type" in period $t$. Here $u^{b}(c ; \xi)$ and $u^{s}(c ; \xi)$ are two different period utility functions, each of which may also be shifted by the vector of aggregate taste shocks, $\xi_{t}$ and $v^{b}(h ; \xi)$ and $v^{s}(h ; \xi)$ are correspondingly two different functions indicating the period disutility from working for the two types. As in the basic NK model, there is assumed to be a continuum of differentiated goods, each produced by a monopolistically competitive supplier; $c_{t}(i)$ is a Dixit-Stiglitz aggregator of the household's purchases of these differentiated goods. The household similarly supplies a continuum of different types of specialized labor, indexed by $j$, that are hired by firms in different sectors of the economy; the additively separable disutility of work, $v^{\tau}(h ; \xi)$, is the same for each type of labor, though it depends on the household's type and the common taste shock.

Each agent's type, $\tau_{t}(i)$, evolves as an independent two-state Markov chain. Specifically, we assume that each period, with probability $1-\delta$ (for some $0 \leq \delta<1$ ), an event occurs that results in a new type for the household being drawn; otherwise it remains the same as in the previous period. When a new type is drawn, it is $b$ with probability $\pi_{b}$ and $s$ with probability $\pi_{s}$, where $0<\pi_{b}, \pi_{s}<1, \pi_{b}+\pi_{s}+1$. (Hence the population fractions of the two types are constant at all times and equal to $\pi_{\tau}$ for each type $\tau$.) We assume moreover that $u_{c}^{b}(c ; \xi)>u_{c}^{s}(c ; \xi)$ when expenditure, $c$, falls in the range of values that occur in equilibrium. (See Figure 5, where these functions are graphed in the case of the calibration, which shows the functions $u_{c}^{b}(c)$ and $u_{c}^{s}(c)$ used in the numerical work reported here.) Hence a change in a household's type changes its relative impatience to consume, given the aggregate state $\xi_{t}$; in addition, each household's current impatience to consume depends on the aggregate state $\xi_{t}$. We also assume that the marginal utility of additional expenditure diminishes at different rates for the two household types (see Figure 5); type $b$ households (who are borrowers in equilibrium) have a marginal utility that varies less with the current level of expenditure, resulting in a greater degree of intertemporal substitution of their expenditures in response to interest rate changes. Finally, the two types are also assumed to differ in the marginal disutility of working a given number of hours; this difference is calibrated so that the two types choose to work the same number of hours in steady state, despite their differing marginal utilities of income. For simplicity, the elasticities of labor supply of the two types are not assumed to differ.

The coexistence of the two types with differing impatience to consume creates a social function for financial intermediation. In the present model, as in the basic NK model, all output is consumed either by households or by the government; hence intermediation serves an allocative function only to the extent that there are reasons for the intertemporal marginal rates of substitution of households to differ in the absence of financial flows. The present model reduces to the standard representative-household model in the case that one assumes that $u^{b}(c ; \xi)=u^{s}(c ; \xi)$ and $v^{b}(h ; \xi)=$ $v^{s}(h ; \xi)$.

We assume the following: that households generally are able to spend an amount different from their current income only by depositing funds with or borrowing from financial intermediaries; that the same nominal interest rate $i_{t}^{d}$ is available to all savers; and that a (possibly) different nominal interest $i_{t}^{b}$ is available to all borrowers, ${ }^{5}$ independent of the quantities that a given household chooses to save or to borrow. For simplicity, we also assume that only one-period riskless nominal contracts with the intermediary are possible for either savers and borrowers. The assumption that households cannot engage in financial contracting other than through the inter-

\footnotetext{
5 Here "savers" and "borrowers" identify households according to whether they choose to save or borrow and not according to their type.
} 


\section{Figure 5}

\section{Marginal Utilities of Consumption for Two Household Types}

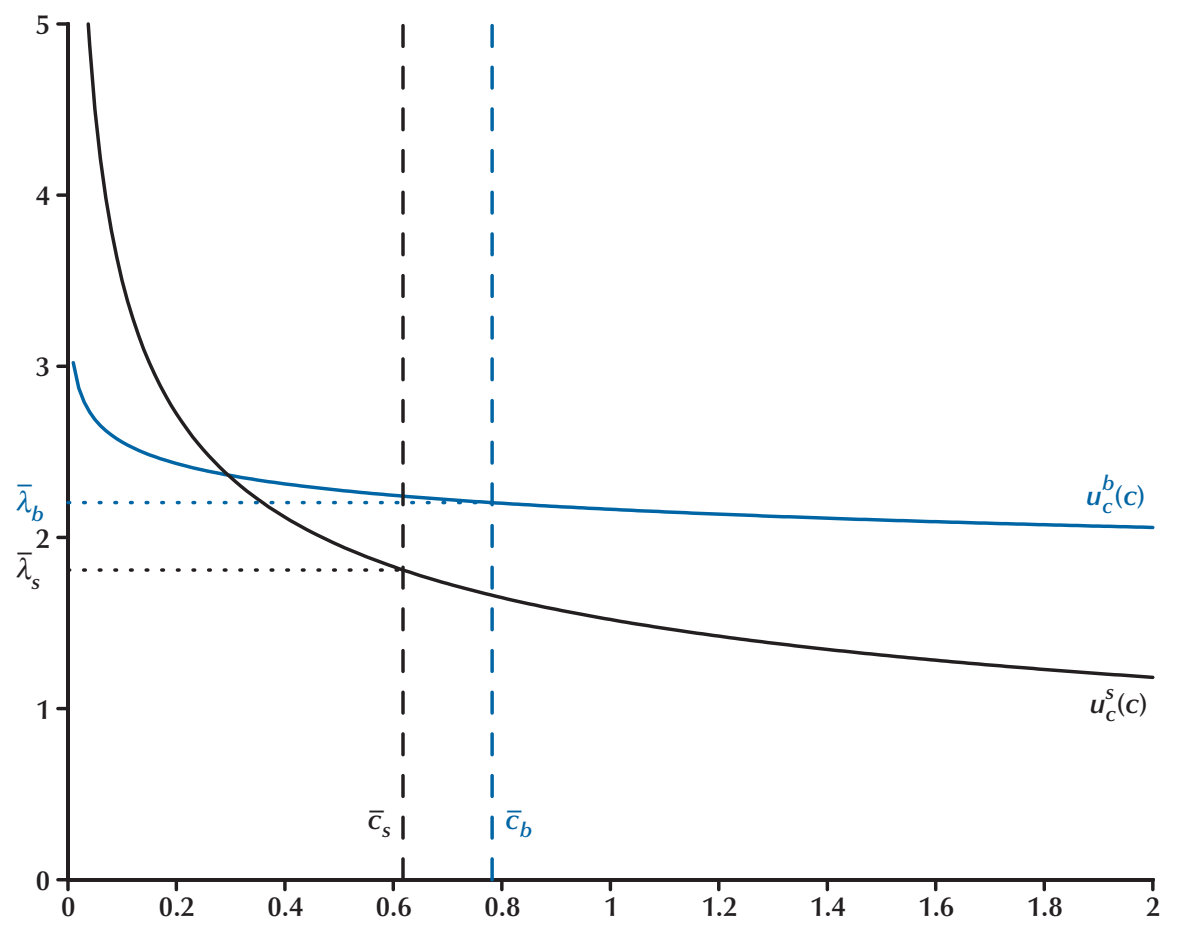

NOTE: The values of $\bar{c}^{s}$ and $\bar{c}^{b}$ indicate steady-state consumption levels of the two types, and $\bar{\lambda}^{s}$ and $\bar{\lambda}^{b}$ their corresponding steadystate marginal utilities.

mediary sector represents one of the key financial frictions. We also allow households to hold oneperiod riskless nominal government debt. But, because government debt and deposits with intermediaries are perfect substitutes as investments, households must pay the same interest rate $i_{t}^{d}$ in equilibrium and their decision problem is the same as the case in which they have only one decision about how much to deposit with or borrow from intermediaries.

Aggregation is simplified by assuming that households are able to sign state-contingent contracts with one another, through which they may insure one another against both aggregate risk and the idiosyncratic risk associated with a household's random draw of its type, but also assuming that households are only intermittently able to receive transfers from the insurance agency; between these infrequent occasions when a household has access to the insurance agency, it can only save or borrow through the financial intermediary sector mentioned previously. The assumption that households are eventually able to make transfers to one another in accordance with an insurance contract signed earlier means that they continue to have identical expectations regarding their marginal utilities of income far enough in the future, regardless of their differing type histories.

It then turns out that in equilibrium, the marginal utility of a given household at any point in time depends only on its type $\tau_{t}(i)$ at that time; hence the entire distribution of marginal utilities of income at any time can be summarized by two state variables, $\lambda_{t}^{b}$ and $\lambda_{t}^{s}$, indicating the marginal utilities of each of the two household types. The 
expenditure level of type $\tau$ is also the same for all households of that type and can be obtained by inverting the marginal-utility functions (graphed in Figure 5) to yield an expenditure demand function $c^{\tau}\left(\lambda ; \xi_{t}\right)$ for each type. Aggregate demand $Y_{t}$ for the Dixit-Stiglitz composite good can then be written as

(2) $Y_{t}=\pi_{b} c^{b}\left(\lambda_{t}^{b} ; \xi_{t}\right)+\pi_{s} c^{s}\left(\lambda_{t}^{s} ; \xi_{t}\right)+G_{t}+\Xi_{t}$,

where $G_{t}$ indicates the (exogenous) level of government purchases, and $\Xi_{t}$ indicates resources consumed by intermediaries (the sum of two components, $X i_{t}^{p}$ representing costs of the private intermediaries and $\Xi_{t}^{c b}$ representing costs of central bank activities, each discussed further below). Thus the effects of financial conditions on aggregate demand can be summarized by tracking the evolution of the two state variables $\lambda_{t}^{\tau}$. The marginal-utility ratio $\Omega_{t} \equiv \lambda_{t}^{b} / \lambda_{t}^{s} \geq 1$ provides an important measure of the inefficiency of the allocation of expenditure owing to imperfect financial intermediation-since, in the case of frictionless financial markets, we would have $\Omega_{t}=1$ at all times.

In the presence of heterogeneity, instead of a single Euler equation each period relating the path of the marginal utility of income of the representative household to the model's single interest rate, we have two Euler equations each period, one for each household type and each involving a different interest rate: $i_{t}^{b}$ for type $b$ households (who choose to borrow in equilibrium) and $i_{t}^{d}$ for type $s$ households (who choose to save). If we loglinearize these Euler equations, ${ }^{6}$ and combine them with a log-linearized version of (2), we obtain a structural relation of the form

$$
\begin{aligned}
& \hat{Y}_{t}=-\bar{\sigma}\left(\hat{\imath}_{t}^{a v g}-E_{t} \pi_{t+1}\right)+E_{t} \hat{Y}_{t+1}-E_{t} \Delta g_{t+1} \\
& -E_{t} \Delta \hat{\Xi}_{t+1}-\bar{\sigma} s_{\Omega} \hat{\Omega}_{t}+\bar{\sigma}\left(s_{\Omega}+\psi_{\Omega}\right) E_{t} \hat{\Omega}_{t+1}
\end{aligned}
$$

generalizing the "intertemporal IS relation" of the basic NK model. Here $\hat{Y}_{t} \equiv \log \left(Y_{t} / \bar{Y}\right)$ measures

\footnotetext{
6 Here and in the case of all other log-linearizations discussed below, we log-linearize around a deterministic steady state in which the inflation rate is zero and aggregate output is constant.
}

the percentage deviation of aggregate output from its steady-state level;

$$
\hat{\imath}_{t}^{a v g} \equiv \pi_{b} \hat{\imath}_{t}^{b}+\pi_{s} \hat{\underline{1}}_{t}^{d}
$$

is the average of the interest rates that are relevant (at the margin) for all of the savers and borrowers in the economy, where we define $\hat{\imath}_{t}^{\tau} \equiv \log \left(1+i_{t}^{\tau} / 1+\bar{I}^{\tau}\right)$ for $\tau \in\{b, d\} ;^{7} g_{t}$ is a composite "autonomous expenditure" disturbance as in Woodford (2003, pp. 80, 249), taking account of exogenous fluctuations in $G_{t}$, as well as exogenous variation in the spending opportunities facing the two types of households (reflected in the dependence of the functions $u^{\tau}\left(c ; \xi_{t}\right)$ on the state vector $\left.\xi_{t}\right) ; \hat{\Xi}_{t} \equiv\left(\Xi_{t}-\bar{\Xi}\right) / \bar{Y}$ measures departures of the quantity of resources consumed by the intermediary sector from its steady-state level ${ }^{8}$; and $\hat{\Omega}_{t} \equiv \log \left(\Omega_{t} / \bar{\Omega}\right)$ measures the gap between the marginal utilities of the two household types.

Note that the first four terms on the right-hand side of (3) are exactly as in the basic NK model, except for these differences: (i) instead of "the" interest rate we have an average interest rate; (ii) $\bar{\sigma}$ is no longer the intertemporal elasticity of substitution for the representative household, but instead a weighted average of the corresponding parameters for the two types; and (iii) the composite disturbance, $g_{t}$, similarly averages the changes in spending opportunities for the two types. The crucial differences are the presence of the new terms involving $\hat{\Xi}_{t}$ and $\hat{\Omega}_{t}$, which exist only in the case of financial frictions. The sign of the coefficient $s_{\Omega}$ depends on the asymmetry of the degrees of interest sensitivity of expenditure by the two types; in the case shown in Figure 5 (which we regard as the empirically relevant case), $s_{\Omega}>0$ because the intertemporal elasticity of expenditure is higher for type $b .{ }^{9}$ In this case, a larger value of $\hat{\Omega}_{t}$ reduces aggregate demand for given expectations about the forward path of average

\footnotetext{
7 One can show that, for a log-linear approximation, the average marginal utility of income in the population depends only on the expected path of this particular average of the interest rates in the economy.

8 We adopt this notation so that $\hat{\Xi}_{t}$ is defined even when the model is parameterized so that $\bar{\Xi}=0$.

9 In our calibration, $\psi_{\Omega}$ is a small negative quantity, but because it is small its sign is not of great importance.
} 
real interest rates; this can be thought of as representing "financial headwinds" of a kind sometimes discussed within the Federal Reserve system. ${ }^{10}$

Log-linearization of the two Euler equations also implies that

(4) $\hat{\Omega}_{t}=\hat{\omega}_{t}+\hat{\delta} E_{t} \hat{\Omega}_{t+1}$,

where $\omega_{t} \hat{\imath}_{t}^{b}-\hat{\imath}_{t}^{d}$ is the short-term credit spread and $\hat{\delta}$ is a coefficient satisfying $0<\hat{\delta}<1$. Thus the marginal-utility gap, $\hat{\Omega}_{t}$, is a forward-looking moving average of the expected path of the short-term credit spread. Alternatively, we can view $\hat{\Omega}_{t}$ itself as a credit spread, a positive multiple of the spread between two long-term yields,

$$
r_{t}^{\tau} \equiv(1-\hat{\delta})^{-1} \sum_{j=0}^{\infty} \hat{\delta}^{j} E_{t} \hat{\imath}_{t+j}^{\tau}
$$

for $\tau \in\{b, d\}$. Hence the terms in (3) involving $\hat{\Omega}_{t}$ indicate that variations in credit spreads are relevant to aggregate demand. Credit spreads are also relevant to the relation between the path of the policy rate ${ }^{11}$ and aggregate expenditure because of the identity

(5) $\hat{\imath}_{t}^{\text {avg }}=\hat{\imath}_{t}^{d}+\pi_{b} \hat{\omega}_{t}$

connecting the policy rate to the interest rate that appears in (3). Under an assumption of Calvostyle staggered price adjustment, we similarly obtain an aggregate supply relation that is only slightly different from the "NK Phillips curve" of the representative-household model. Specifically, we obtain

$$
\pi_{t}=\kappa\left(\hat{Y}_{t}-\hat{Y}_{t}^{n}\right)+\beta E_{t} \pi_{t+1}+u_{t}+\kappa_{\Omega} \hat{\Omega}_{t}-\kappa_{\Xi} \hat{\Xi}_{t},
$$

where $\hat{Y}_{t}^{n}$ (the "natural rate of output") is a composite exogenous disturbance that depends on technology, preferences, and government purchases; $u_{t}$ (the "cost-push shock") is another com-

\footnotetext{
${ }^{10}$ See, for example, the reference by Alan Greenspan (1997) to the U.S. economy in the early 1990s as "trying to advance in the face of fifty-mile-an-hour headwinds," owing to "severe credit constraint." The point of the metaphor was that under such conditions, a given reduction in the federal funds rate stimulated less expenditure than it ordinarily would have.

${ }^{11}$ The identification of $i_{t}^{d}$ with the policy rate is discussed below in Section 1.3.
}

posite exogenous disturbance that depends on variations in distorting taxes and in the degree of market power in labor or product markets; and the coefficients satisfy $\kappa, \kappa_{\Xi}>0$ and, in the case that we regard as realistic, $\kappa_{\Omega}>0$ as well. Here the first three terms on the right-hand side are identical to those of the standard "NK Phillips curve," subject to similar comments as above about the dependence of $\kappa$ on a weighted average of the intertemporal elasticities of substitution of the two types and the dependence of $\hat{Y}_{t}^{n}$ on a weighted average of the preference shocks of the two types; the final two terms appear only as a result of credit frictions. We note in particular that increases in credit spreads shift both the aggregate-supply and aggregate-demand relations in our model.

In the presence of heterogeneity, household behavior results in one further structural equation that has no analog in the representative-household model. This is a law of motion for $b_{t}$, the per capita level of private borrowing, which depends on the fluctuations in the levels of expenditure of the two types and, hence, on the fluctuations in both marginal utilities $\lambda_{t}^{\tau}$. Details of this additional relationship are provided in Cúrdia and Woodford (2009a). We also suppose that the government issues one-period riskless nominal debt, the real value of which at the end of period $t$ is denoted $b_{t}^{g}$. We treat $\left\{b_{t}^{g}\right\}$ as an exogenous process; this is one of three independent fiscal disturbances that we allow for. ${ }^{12}$ We suppose that government debt can be held either by saving households or by the central bank, ${ }^{13}$ and in equilibrium we suppose that at least part of the public debt is always held by households. Since government debt is a perfect substitute for deposits with the intermediaries in our model, from the standpoint of saving households, in equilibrium the yield on government debt must always equal $i_{t}^{d}$, the competitive interest rate on deposits.

\footnotetext{
12 The other two disturbances are exogenous variations in government purchases, $G_{t}$, of the composite good and exogenous variations in a proportional sales tax rate.

${ }^{13}$ We could also allow intermediaries to hold government debt, but they will choose not to as long as $i_{t}^{b}>i_{t}^{d}$, as is always true in the equilibria that we consider.
} 


\subsection{Financial Intermediaries}

We assume an intermediary sector made up of identical, perfectly competitive firms. Intermediaries take deposits on which they promise to pay a riskless nominal return, $i_{t}^{d}$, one-period later, and make one-period loans on which they demand a nominal interest rate $i_{t}^{b}$. An intermediary also chooses a quantity of reserves, $M_{t}$, to hold at the central bank, on which it will receive a nominal interest yield $i_{t}^{m}$. Each intermediary takes as given all three of these interest rates. We assume that arbitrage by intermediaries need not eliminate the spread between $i_{t}^{b}$ and $i_{t}^{d}$ for either of two reasons: (i) Resources are used in the process of loan origination or (ii) intermediaries may be unable to tell the difference between good borrowers (who will repay their loans the next period) and bad borrowers (who will be able to disappear without having to pay) and as a consequence may have to charge a higher interest rate to good and bad borrowers alike.

We suppose that origination of good loans in real quantity $L_{t}$ requires an intermediary to also originate bad loans in quantity $\chi_{t}\left(L_{t}\right)$, where $\chi_{t}^{\prime}$, $\chi_{t}^{\prime \prime} \geq 0$, and the function $\chi_{t}(L)$ may shift from period to period for exogenous reasons. (While the intermediary is assumed to be unable to discriminate between good and bad loans, it is able to predict the fraction of loans that will be bad in the case of any given scale of its lending activity.) This scale of operations also requires the intermediary to consume real resources $\Xi_{t}^{p}\left(L_{t} ; m_{t}\right)$ in the period in which the loans are originated, where $m_{t} \equiv M_{t} / P_{t}$, and $\Xi_{t}^{p}(L ; m)$ is a convex function of its two arguments, with $\Xi_{L t}^{p} \geq 0, \Xi_{m t}^{p} \leq 0$, $\Xi_{L m t}^{p} \leq 0$. We further suppose that for any scale of operations, $L$, there exists a finite satiation level of reserve balances, $\bar{m}_{t}(L)$, defined as the lowest value of $m$ for which $\Xi_{m t}^{p}(L ; m)=0$. (Our convexity and sign assumptions then imply that $\Xi_{m t}^{p}(L ; m)=0$ for all $m>\bar{m}_{t}(L)$.) We assume the existence of a finite satiation level of reserves for an equilibrium to be possible in which the policy rate is driven to zero, a situation of considerable practical relevance at present.

Given an intermediary's choice of its scale of lending operations, $L_{t}$, and reserve balances, $m_{t}$, to hold, we assume that it acquires real deposits, $d_{t}$, in the maximum quantity that it can repay (with interest at the competitive rate) from the anticipated returns on its assets (taking into account the anticipated losses on bad loans). Thus it chooses $d_{t}$ such that

$$
\left(1+i_{t}^{d}\right) d_{t}=\left(1+i_{t}^{b}\right) L_{t}+\left(1+i_{t}^{m}\right) m_{t} .
$$

The deposits that it does not use to finance either loans or the acquisition of reserve balances,

$$
d_{t}-m_{t}-L_{t}-\chi_{t}\left(L_{t}\right)-\Xi_{t}^{p}\left(L_{t} ; m_{t}\right),
$$

are distributed as earnings to its shareholders. The intermediary chooses $L_{t}$ and $m_{t}$ each period to maximize these earnings, given $i_{t}^{d}, i_{t}^{b}, i_{t}^{m}$. This implies that $L_{t}$ and $m_{t}$ must satisfy the first-order conditions:

(7) $\Xi_{L t}^{p}\left(L_{t} ; m_{t}\right)+\chi_{L t}\left(L_{t}\right)=\omega_{t} \equiv \frac{i_{t}^{b}-i_{t}^{d}}{1+i_{t}^{d}}$,

(8) $-\Xi_{m t}^{p}\left(L_{t} ; m_{t}\right)=\delta_{t}^{m} \equiv \frac{i_{t}^{d}-i_{t}^{m}}{1+i_{t}^{d}}$.

Equation (7) can be viewed as determining the equilibrium credit spread, $\omega_{t}$, as a function $\omega_{t}\left(L_{t} ; m_{t}\right)$ of the aggregate volume of private credit and the real supply of reserves. ${ }^{14}$ As indicated above, a positive credit spread exists in equilibrium to the extent that $\Xi_{t}^{p}(L ; m), \chi_{t}(L)$, or both are increasing in $L$. Equation (8) similarly indicates how the equilibrium differential $\delta_{t}^{m}$ between the interest paid on deposits and that paid on reserves at the central bank is determined by the same two aggregate quantities.

In addition to these two equilibrium conditions that determine the two interest rate spreads in the model, the absolute level of (real) interest rates must be such that the supply and demand for credit are equal. Market clearing in the credit market requires that

(9) $b_{t}=L_{t}+L_{t}^{c b}$,

\footnotetext{
${ }^{14}$ Note that in terms of this definition of the credit spread, $\omega_{t}$, the previously defined deviation corresponds to $\hat{\omega}_{t} \equiv \log \left(1+\omega_{t} / 1+\bar{\omega}\right)$.
} 
where $L_{t}^{c b}$ represents real lending to the private sector by the central bank, as discussed next.

\subsection{The Central Bank and Interest Rate Determination}

In our model, the central bank's liabilities consist of the reserves, $M_{t}$, (which also constitute the monetary base) on which it pays interest at the rate $i_{t}^{m}$. These liabilities in turn fund the central bank's holdings of government debt and any lending by the central bank to type $b$ households. We let $L_{t}^{c b}$ denote the real quantity of lending by the central bank to the private sector; the central bank's holdings of government debt are then given by the residual $m_{t}-L_{t}^{c b}$. We can treat $m_{t}$ (or $M_{t}$ ) and $L_{t}^{c b}$ as the bank's choice variables, subject to the following constraints:

(10) $0 \leq L_{t}^{c b} \leq m_{t}$.

It is also necessary that the central bank's choices of these two variables also satisfy the bound

$$
m_{t}<L_{t}^{c b}+b_{t}^{g},
$$

where $b_{t}^{g}$ is the total outstanding real public debt, so that a positive quantity of public debt remains in the portfolios of households. In the calculations below, however, we assume that this last constraint is never binding. (We confirm this in our numerical examples.)

We assume that central bank extension of credit other than through open-market purchases of Treasury securities consumes real resources, just as in the case of private intermediaries, and represent this resource cost by a function $\Xi^{c b}\left(L_{t}^{c b}\right)$, discussed further in Section 4, which is increasing and at least weakly convex, with $\Xi^{c b^{\prime}}(0)>0$.

The central bank has one further independent choice to make each period, which is the rate of interest $i_{t}^{m}$ to pay on reserves. We assume that if the central bank lends to the private sector, it simply chooses the amount that it is willing to lend and auctions these funds, so that in equilibrium it charges the same interest rate $i_{t}^{b}$ on its lending that private intermediaries do; this is therefore not an additional choice variable for the central bank. Similarly, the central bank receives the market-determined yield $i_{t}^{d}$ on its holdings of government debt.

The interest rate $i_{t}^{d}$ at which intermediaries are able to fund themselves is determined each period by the joint inequalities

(11) $m_{t} \geq m_{t}^{d}\left(L_{t}, \delta_{t}^{m}\right)$

(12) $\delta_{t}^{m} \geq 0$,

together with the "complementary slackness" condition that at least one of these-(11) and/or (12) - must hold with equality each period; here $m_{t}^{d}\left(L, \delta^{m}\right)$ is the demand for reserves defined by (8), defined to equal the satiation level $\bar{m}_{t}(L)$ in the case that $\delta^{m}=0$. (Condition (11) may hold only as an inequality, as intermediaries will be willing to hold reserves beyond the satiation level as long as the opportunity cost, $\delta_{t}^{m}$, is zero.) We identify the rate $i_{t}^{d}$ at which intermediaries fund themselves with the central bank's policy rate (e.g., the federal funds rate in the case of the United States).

The central bank can influence the policy rate through two channels: its control of the supply of reserves and its control of the interest rate paid on them. By varying $m_{t}$, the central bank can change the equilibrium differential, $\delta_{t}^{m}$, determined as the solution to (11) and (12). And by varying $i_{t}^{m}$, it can change the level of the policy rate, $i_{t}^{d}$, that corresponds to a given differential. Through appropriate adjustment on both margins, the central bank can control $i_{t}^{d}$ and $i_{t}^{m}$ separately (subject to the constraint that $i_{t}^{m}$ cannot exceed $i_{t}^{d}$ ). We also assume that for institutional reasons, it is not possible for the central bank to pay a negative interest rate on reserves. (We may suppose that intermediaries have the option of holding currency, earning zero interest, as a substitute for reserves, and that the second argument of the resource cost function, $\boldsymbol{\Xi}_{t}^{p}(b ; m)$, is actually the sum of reserve balances at the central bank plus vault cash.) Hence the central bank's choice of these variables is subject to the constraints

(13) $0 \leq i_{t}^{m} \leq i_{t}^{d}$.

In our model, there are thus three independent dimensions along which central bank policy can 
be varied: the quantity of reserves, $M_{t}$, that are supplied; the interest rate $i_{t}^{m}$ paid on those reserves; and the breakdown of central bank assets between government debt and lending $L_{t}^{c b}$ to the private sector. Alternatively, we can specify these three independent dimensions as (i) interest rate policy, the central bank's choice of an operating target for the policy rate, $i_{t}^{d}$; (ii) reserve-supply policy, the choice of $M_{t}$, which in turn implies a unique rate of interest $i_{t}^{m}$ that must be paid on reserves for the reserve-supply policy to be consistent with the bank's target for the policy rate ${ }^{15}$; and (iii) credit policy, the central bank's choice of the quantity of funds $L_{t}^{c b}$ to lend to the private sector. We prefer this last identification of the three dimensions of policy because in this case our first dimension (interest rate policy) corresponds to the sole dimension of policy emphasized in many conventional analyses of optimal monetary policy; the first two are additional dimensions of policy introduced by our extension of the basic NK model. ${ }^{16}$ Changes in central bank policy along each of these dimensions has consequences for the bank's cash flow, but we abstract from any constraint on the joint choice of the three variables associated with cash-flow concerns. (We assume that seignorage revenues are simply turned over to the Treasury, where their only effect is to change the size of lump-sum transfers to the households.)

Given that central bank policy can be independently varied along each of these three dimensions, we can independently discuss the criteria for policy to be optimal along each dimension. Below, we take up each of the three dimensions in turn.

\footnotetext{
${ }^{15}$ We might choose to call the second dimension "variation in the interest rate paid on reserves," which would correspond to something that the Board of Governors makes an explicit decision about under current U.S. institutional arrangements, as is also true at most other central banks. But describing the second dimension of policy as "reserve-supply policy" allows us to address the question of the value of "quantitative easing" under this heading as well.

${ }^{16}$ Goodfriend (2009) similarly describes central bank policy as involving three independent dimensions. These correspond to our first three dimensions, but he calls the first dimension (the quantity of reserves, or base money) "monetary policy." We believe that this does not correspond to standard usage of the term "monetary policy," since the traditional focus of Federal Open Market Committee (FOMC) deliberations about monetary policy has been the choice of an operating target for the policy rate, as is generally the case for central banks. Reis (2009) also distinguishes among the three dimensions of policy in terms similar to ours.
}

\subsection{The Welfare Objective}

In considering optimal policy, we take the objective of policy to be the maximization of average expected utility. Thus we can express the objective as maximization of

$$
E_{t_{0}} \sum_{t=t_{0}}^{\infty} \beta^{t-t_{0}} U_{\mathrm{t}}
$$

where the welfare contribution, $U_{t}$, each period weights the period utility of each of the two types by their respective population fractions at each point in time. As shown in Cúrdia and Woodford (2009a), ${ }^{17}$ this can be written as

$$
\text { (15) } U_{t}=U\left(Y_{t}, \Omega_{t}, \Xi_{t}, \Delta_{t} ; \xi_{t}\right) \text {. }
$$

Here $\Delta_{t}$ is an index of price dispersion in period $t$, taking its minimum possible value of 1 when the prices of all goods are identical; for any given total quantity $Y_{t}$ of the composite good that must be produced, the total disutility of working indicated in (1) is greater the more dispersed are prices, as this implies a correspondingly less uniform (and hence less efficient) composition of output.

The total disutility of working is also a decreasing function of $\Omega_{t}$, since a larger gap between the marginal utilities of the two types implies a lessefficient division of labor effort between the two types. The average utility from consumption is smaller, for given aggregate output $Y_{t}$, the larger is $\Xi_{t}$, since only resources $Y_{t}-G_{t}-\Xi_{t}$ are consumed by households. And the average utility from consumption is also decreasing in $\Omega_{t}$, since a larger marginal-utility gap implies a less-efficient division of expenditure between the two types. Thus the derived utility $U(\cdot)$ is a concave function of $Y_{t}$ that reaches an interior maximum for given values of the other arguments, and a monotonically decreasing function of $\Omega_{t}, \Xi_{t}$, and $\Delta_{t}$. The

\footnotetext{
${ }^{17}$ Cúrdia and Woodford (2009a) analyze a special case of the present model in which central bank lending and the role of central bank liabilities in reducing the transactions costs of intermediaries are abstracted from. However, the form of the welfare measure (15) depends only on the nature of the heterogeneity in our model, and the assumed existence of a credit spread and of resources consumed by the intermediary sector; the functions that determine how $\Omega_{t}$ and $\Xi_{t}$ are endogenously determined are irrelevant for this calculation, and those are the only parts of the model that are generalized in this paper. Hence the form of the welfare objective in terms of these variables remains the same.
} 
dependence of $U(\cdot)$ on $Y_{t}$ and $\Delta_{t}$ is the same as in the representative-household model of Benigno and Woodford (2005), while the dependence on $\Omega_{t}$ and $\Xi_{t}$ indicates new distortions resulting from the credit frictions in our model.

As in Benigno and Woodford, the assumption of Calvo-style price adjustment implies that the index of price dispersion evolves according to a law of motion of the form

$$
\Delta_{t}=h\left(\Delta_{t-1}, \pi_{t}\right)
$$

where for a given value of $\Delta_{t-1}, h\left(\Delta_{t-1}, \cdot\right)$ has an interior minimum at an inflation rate that is near zero when $\Delta_{t-1}$ is near 1 . Thus for given paths of the variables $\left\{\Omega_{t}, \Xi_{t}\right\}$ welfare is maximized by trying (to the extent possible) to simultaneously keep aggregate output near the (time-varying) level that maximizes $U$ and inflation near the (always low) level that minimizes price dispersion. Hence our model continues to justify concerns about output and inflation stabilization common to the NK literature. However, it also implies that welfare can be increased by reducing credit spreads and the real resources consumed in financial intermediation. These latter concerns make the effects of policy on the evolution of aggregate credit and on the supply of bank reserves also relevant to monetary policy deliberations. We now turn to the question of how each of the three dimensions of central bank policy can effect these several objectives.

\section{OPTIMAL POLICY: THE SUPPLY OF RESERVES}

We shall first consider optimal policy with regard to the supply of reserves, taking as given (for now) the way in which the central bank chooses its operating target for the policy rate, $i_{t}^{d}$ and the state-contingent level of central bank lending to the private sector, $L_{t}^{c b}$. Under fairly weak assumptions, we obtain a very simple result: Optimal policy requires that intermediaries be satiated in reserves, that is, that $M_{t} / P_{t} \geq \bar{m}_{t}\left(L_{t}\right)$ at all times.

For levels of reserves below the satiation point, an increase in the supply of reserves has two effects relevant for welfare: The resource cost of financial intermediation, $\Xi_{t}^{p}$, is reduced (for a given level of lending by the intermediary sector), and the credit spread, $\omega_{t}$, is reduced (again, for a given level of lending) as a consequence of (7). Each of these effects raises the value of the objective in (14); note that the reductions in credit spreads increase welfare because of their effect on the path of the marginal-utility gap, $\Omega_{t}$, as a consequence of (4). Hence an increase in the supply of reserves is unambiguously desirable in any period in which they remain below the satiation level. ${ }^{18}$ Once reserves are at or above the satiation level, however, further increases reduce neither the resource costs of intermediaries nor equilibrium credit spreads (as in this case, $\boldsymbol{\Xi}_{m t}^{p}=\boldsymbol{\Xi}_{L m t}^{p}=0$ ), so there would be no further improvement in welfare. Hence policy is optimal along this dimension if and only if $M_{t} / P_{t} \geq \bar{m}_{t}\left(L_{t}\right)$ at all times, ${ }^{19}$ so that

(16) $\Xi_{m t}^{p}\left(L_{t} ; m_{t}\right)=0$.

This is just another example in which the familiar Friedman rule for "the optimum quantity of money" (Friedman, 1969) applies. Note, however, that our result has no consequences for interest rate policy. While the Friedman rule is sometimes taken to imply a strong result about the optimal control of short-term nominal interest rates-namely, that the nominal interest rate should equal zero at all times-the efficiency condition (16), together with the equilibrium relation (8), implies only that the interest rate differential, $\delta_{t}^{m}$, should equal zero at all times. With zero interest on reserves, this would also require that $i_{t}^{d}=0$ at all times; but given that the central bank is free to set any level of interest on reserves consistent with (13), the efficiency condition (16) actually implies no restriction on either the average level or the degree of state-contingency of the central bank's target for the policy rate, $i_{t}^{d}$.

\footnotetext{
${ }^{18}$ The discussion here assumes that the upper bound in (10) is not a binding constraint. But if that constraint does bind, then an increase in the supply of reserves relaxes the constraint, and this too increases welfare, so that the conclusion in the text is unchanged.

${ }^{19}$ To be more precise, policy is optimal if and only if (16) is satisfied and the upper bound in (10) does not bind. Both conditions will be satisfied by any quantity of reserves above some finite level.
} 


\subsection{Is a Reserve-Supply Target Needed?}

Our result about the importance of ensuring an adequate supply of reserves might suggest that the question of the correct target level of reserves at each point in time should receive the same degree of attention at meetings of the FOMC as the question of the correct operating target for the federal funds rate. But deliberations of that kind are not needed to ensure fulfillment of the optimality criterion (16); the efficiency condition can alternatively be stated (using (8)) as requiring that $i_{t}^{d}=i_{t}^{m}$ at all times. Reserves should be supplied to the point at which the policy rate falls to the level of the interest rate paid on reserves, or, in a formulation that is more to the point, interest should be paid on reserves at the central bank's target for the policy rate.

Given a rule for setting an operating target for $i_{t}^{d}$ (discussed in the next section), $i_{t}^{m}$ should be chosen each period in accordance with the simple rule

(17) $i_{t}^{m}=i_{t}^{d}$.

When the central bank implements its target for the policy rate through open-market operations, it will automatically have to adjust the supply of reserves to satisfy (16). But this does not require a central bank's monetary policy committee (the FOMC in the case of the United States) to deliberate about an appropriate target for reserves at each meeting; once the target for the policy rate is chosen (and the interest rate to be paid on reserves is determined by that, through condition (17)), the quantity of reserves that must be supplied to implement the target can be determined by the bank staff in charge of carrying out the necessary interventions (the Trading Desk at the New York Fed in the case of the United States), on the basis of a more frequent monitoring of market conditions than is possible for the monetary policy committee.

One obvious way to ensure that the efficiency condition (17) is satisfied is to adopt a routine practice of automatically paying interest on reserves at a rate that is tied to the current operating target for the policy rate. This is already the practice of many central banks outside the United
States. At some of those banks, the fixed spread between the target for the policy rate and the rate paid on overnight balances at the central bank is quite small: for example, 25 basis points in the case of the Bank of Canada; in the case of New Zealand, the interest rate paid on overnight balances is the policy rate itself. There are possible arguments (relating to considerations not reflected in our simple model) why the optimal spread might be larger than zero, but it is likely in any event to be desirable to maintain a constant small spread rather than treat the question of the interest rate to be paid on reserves as a separate, discretionary policy decision to be made at each policy committee meeting. Apart from the efficiency gains modeled here, such a system should also help to facilitate the central bank's control of the policy rate (Goodfriend, 2002, and Woodford, 2003, Chap. 1, Sec. 3).

\subsection{Is There a Role for "Quantitative Easing"?}

While our analysis implies that it is desirable to ensure that the supply of reserves never falls below a certain lower bound, $\bar{m}_{t}\left(L_{t}\right)$ it also implies that there is no benefit from supplying reserves beyond that level. There is, however, one important exception to this assertion: It can be desirable to supply reserves beyond the satiation level if this is necessary to make the optimal quantity of central bank lending to the private sector, $L_{t}^{c b}$, consistent with (10). This qualification is important when considering the desirability of the massive expansion in the supply of reserves by the Fed since September 2008, as shown in Figure 2. The increase in reserves (shown in Figure 4) occurred only after the Fed expanded the various newly created liquidity and credit facilities beyond the scale that could be financed simply by reducing its holdings of Treasury securities (as had been its policy over the previous year). ${ }^{20}$

Some have argued, instead, that further expansion of the supply of reserves beyond the level

\footnotetext{
${ }^{20}$ Bernanke (2009) distinguishes between the Federal Reserve policy of "credit easing" and the type of "quantitative easing" practiced by the Bank of Japan earlier in the decade, essentially on this ground.
} 
needed to bring the policy rate down to the level of the rate of interest paid on reserves is an important additional policy tool in its own right-one of particular value precisely when a central bank is no longer able to further reduce its operating target for the policy rate, owing to the zero lower bound (as at present in the United States and many other countries). It is sometimes proposed that when the zero lower bound is reached, it is desirable for a central bank's policy committee to shift from deliberations, about an interest rate target to a target for the supply of bank reserves, as under the Bank of Japan's policy of "quantitative easing" during the period between March 2001 and March 2006.

Our model provides no support for the view that such a policy should be effective in stimulating aggregate demand. Indeed, it is possible to state an irrelevance proposition for quantitative easing in the context of our model. Let the three dimensions of central bank policy be described by functions that specify the operating target for the policy rate, the supply of reserves, the interest rate to be paid on reserves, and the quantity of central bank credit as functions of macroeconomic conditions. For the sake of concreteness, we may suppose that each of these variables is to be determined by a Taylor-type rule,

$$
\begin{aligned}
i_{t}^{d} & =\phi^{i d}\left(\pi_{t}, Y_{t}, L_{t} ; \xi_{t}\right), \\
M_{t} / P_{t} & =\phi^{m}\left(\pi_{t}, Y_{t}, L_{t} ; \xi_{t}\right), \\
i_{t}^{m} & =\phi^{i m}\left(\pi_{t}, Y_{t}, L_{t} ; \xi_{t}\right), \\
L_{t}^{c b} & =\phi^{L}\left(\pi_{t}, Y_{t}, L_{t} ; \xi_{t}\right),
\end{aligned}
$$

where the functions are such that constraints in (10) through (13) are satisfied for all values of the arguments. (Here the vector of exogenous disturbances, $\xi_{t}$, on which the reaction functions may depend, includes the exogenous factors that shift the function $\Xi_{t}^{p}(L ; m)$.) Then our result is that, given the three functions $\phi^{i d}(\cdot), \phi^{i m}(\cdot)$, and $\phi^{L}(\cdot)$, the set of processes $\left\{\pi_{t}, Y_{t}, L_{t}, b_{t}, i_{t}^{d}, i_{t}^{b}, \Omega_{t}, \Delta_{t}\right\}$ that constitute possible rational expectations equilibria is the same independent of the choice of the function $\phi^{m}(\cdot)$ as long as the specification of $\phi^{m}(\cdot)$ is consistent with the other three functions (in the sense that (10) and (11) are necessarily satis- fied and that (11) holds with equality in all cases where (12) is a strict inequality). ${ }^{21}$

Of course, the stipulation that $\phi^{m}(\cdot)$ be consistent with the other functions uniquely determines what the function must be for all values of the arguments for which the functions $i^{d}(\cdot)$ and $i^{m}(\cdot)$ imply that $\delta_{t}^{m}>0$. However, the class of policies considered allows for an arbitrary degree of expansion of reserves beyond the satiation level in the region where those functions imply that $\delta_{t}^{m}=0$, and in particular, for an arbitrary degree of quantitative easing when the zero bound is reached (i.e., when $i_{t}^{d}=i_{t}^{m}=0$ ). The class of policies considered includes the popular proposal under which the quantity of excess reserves should depend on the degree to which a standard Taylor rule (unconstrained by the zero bound) would call for a negative policy rate. Our result implies that there should be no benefits from such policies.

Our result might seem to be contradicted by the analysis of Auerbach and Obstfeld (2005), in which an open market operation that expands the money supply is found to stimulate real activity even when the economy is at the zero bound at the time of the monetary expansion. But their thought experiment does not correspond to pure quantitative easing of the kind contemplated in the above proposition-because they specify monetary policy in terms of a path for the money supply and the policy change that they consider is one that permanently increases the money supply, so that it remains higher after the economy has exited from the "liquidity trap" in which the zero bound is temporarily binding. The contemplated policy change is therefore not consistent with an unchanged reaction function $\phi^{\text {id }}(\cdot)$ for the policy rate, and the effects of the intervention can be understood to be the consequences of the commitment to a different future interest rate policy.

Our result implies only that quantitative easing should be irrelevant under two conditions: when (i) an increase in reserves finances an increase in central bank holdings of Treasury securities, rather than an increase in central bank

\footnotetext{
${ }^{21}$ This result generalizes the irrelevance result for quantitative easing in Eggertsson and Woodford (2003) to a model with heterogeneity and credit frictions.
} 
lending to the private sector, and (ii) policy implies no change in the way that people should expect future interest rate policy to be conducted.

Our model does allow for real effects of an increase in central bank lending, $L_{t}^{c b}$, financed by an increase in the supply of reserves, if privatesector financial intermediation is inefficient ${ }^{22}$; but the real effects of the increased central bank lending in that case are the same whether the lending is financed by an increase in the supply of reserves or by a reduction in central bank holdings of Treasury securities. Our model also allows for real effects of an announcement that interest rate policy in the future will be different, as when a central bank commits itself not to return immediately to its usual Taylor rule as soon as the zero bound ceases to bind, but promises instead to maintain policy accommodation for some time after it would become possible to comply with the Taylor rule (as discussed in the next section). But such a promise (if credible and correctly understood by the private sector) should increase output and prevent deflation to the same extent even if it implies no change in policy during the period when the zero lower bound binds.

While our definition of quantitative easing may seem narrow, the policy of the Bank of Japan during the period 2001-06 fits our definition fairly closely. The Bank of Japan's policy involved the adoption of a series of progressively higher quantitative targets for the supply of reserves. The aim of the policy was understood to be to increase the monetary base, rather than to allow the Bank of Japan to acquire any particular type of assets. The assets purchased were almost entirely Japanese government bonds, since credit allocation to malfunctioning markets was not a goal. There was no suggestion that the targets of policy after the end of the zero-interest-rate period would be any different from before. There was no commitment to maintain the increased quantity of base money in circulation permanently; and,

22 This result differs from that obtained in Eggertsson and Woodford (2003), where changes in the composition of the assets on the central bank's balance sheet are also shown to be irrelevant. That stronger result depends on the assumption of a representative household (as in Eggertsson and Woodford) or, alternatively, frictionless financial intermediation. indeed, once it was judged time to end the zerointerest-rate policy, the supply of reserves was rapidly contracted again (Figure 6).

Our theory suggests that expansion of the supply of reserves under such circumstances should have little effect on aggregate demand, and this seems to have been the case. For example, as is also shown in Figure 6, despite an increase in the monetary base of 60 percent during the first two years of the quantitative easing policy, and an eventual increase of nearly 75 percent, nominal GDP never increased at all (relative to its March 2001 level) during the entire five years of the policy. ${ }^{23}$

\section{OPTIMAL POLICY: INTEREST RATE POLICY}

We turn now to a second dimension of policy, the approach taken by the central bank in determining its operating target for the policy rate (the federal funds rate in the case of the Federal Reserve). In this section, we take for granted that reserve-supply policy is being conducted in the way recommended in the previous section, that is, that the rate of interest on reserves will satisfy (17) at all times. In this case, we can replace the function $\Xi_{t}^{p}\left(L_{t} ; m_{t}\right)$ with

$$
\bar{\Xi}_{t}^{p}\left(L_{t}\right) \equiv \Xi_{t}^{p}\left(L_{t} ; \bar{m}_{t}\left(L_{t}\right)\right)
$$

and the function $\omega_{t}\left(L_{t} ; m_{t}\right)$, defined by the lefthand side of (7), with

$$
\bar{\omega}_{t}\left(L_{t}\right) \equiv \omega_{t}\left(L_{t} ; \bar{m}_{t}\left(L_{t}\right)\right)
$$

since there will be satiation in reserves at all times. ${ }^{24}$ Using these functions to specify the

\footnotetext{
${ }^{23}$ As indicated in Figure 6, over the first two years of the quantitativeeasing policy, nominal GDP fell by more than 4 percent, despite extremely rapid growth of base money. While nominal GDP recovered thereafter, it remained below its 2001:Q1 level over the entire period until 2006:Q4, three quarters after the official end of quantitative easing, by which time the monetary base had been reduced again by more than 20 percent. Moreover, even if the growth of nominal GDP after 2003:Q1 is regarded as a delayed effect of the growth in the monetary base two years earlier, this delayed nominal GDP growth was quite modest relative to the size of the expansion in base money.

${ }^{24}$ Even if at some times $m_{t}$ exceeds $\bar{m}_{t}\left(L_{t}\right)$, this will not affect the values of $\Xi_{t}^{p}$ or $\omega_{t}$.
} 


\section{Figure 6}

\section{The Monetary Base and Nominal GDP for Japan 1990-2009 (seasonally adjusted)}

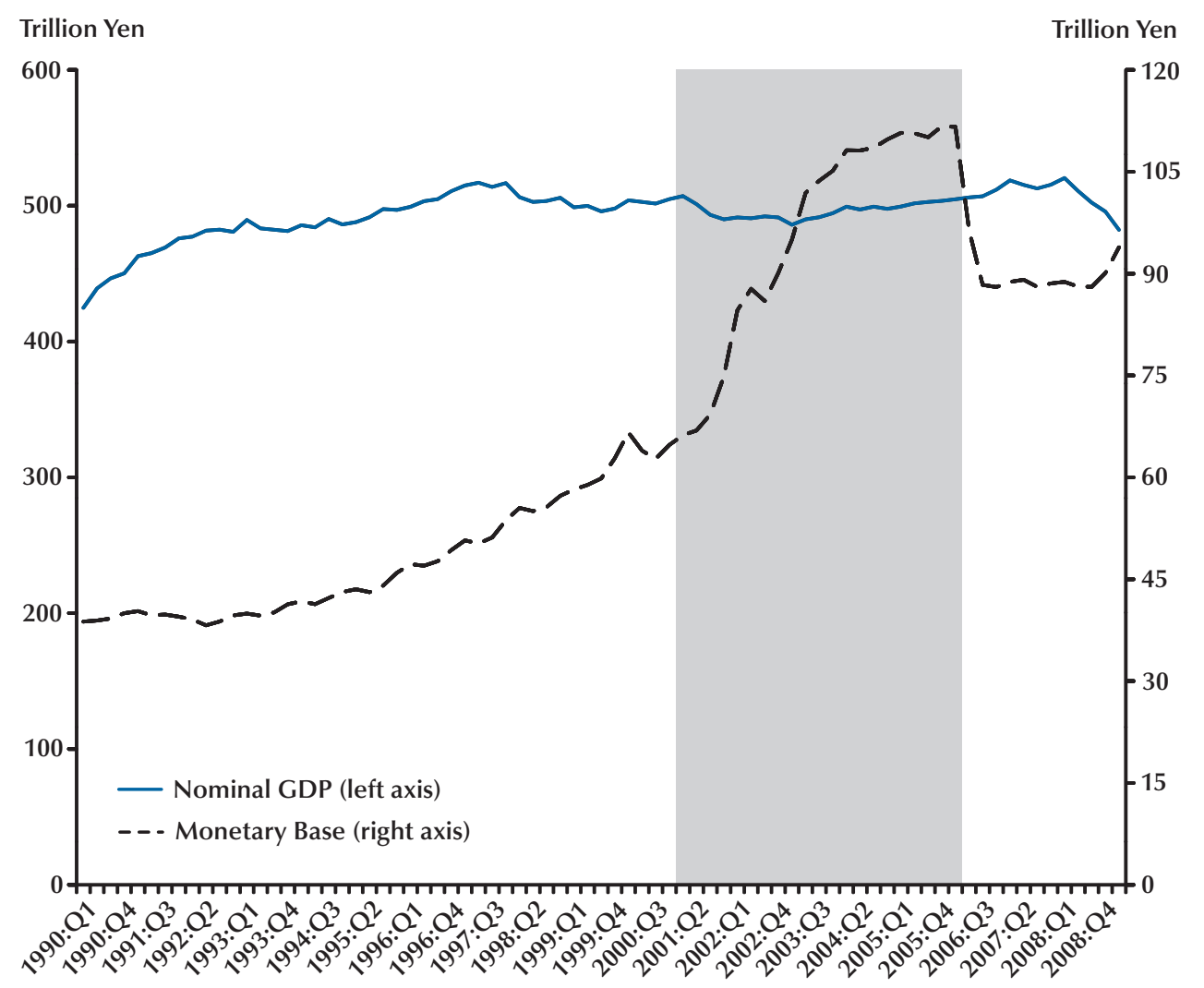

NOTE: The shaded region shows the period of "quantitative easing," from March 2001 through March 2006.

SOURCE: International Monetary Fund International Financial Statistics and Bank of Japan.

equilibrium evolution of $\Xi_{t}^{p}$ and $\omega_{t}$ as functions of the evolution of aggregate private credit, we can then write the equilibrium conditions of the model without any reference to the quantity of reserves or to the interest rate paid on reserves. We shall also take as given the state-contingent evolution of central bank lending $\left\{L_{t}^{c b}\right\}$, and ask how the central bank's target for the policy rate should be adjusted in response to shocks to the economy. In this case the problem considered is of the form considered in Cúrdia and Woodford (2009a).

As in a representative-household model with no financial frictions, a consideration of optimal interest rate policy requires taking into account the desired evolution of aggregate output and of inflation (which affects the objective (14) because of the consequences of inflation for the evolution of the price dispersion index, $\Delta_{t}$ ), given the tradeoff between variations in these two variables implied by the aggregate-supply relation. While our model implies that, in the presence of credit frictions, interest rate policy also has consequences for the evolution of $\Xi_{t}$ and $\Omega_{t}$ (which are also arguments of (15)), owing to its effects on the volume of lending by the intermediary sector, the most important effects are the effects on the paths of output and inflation. The way in which the paths of output and inflation matter for welfare are essentially the same as in a model with- 
out financial frictions, and the nature of the aggregate-supply tradeoff indicated by (6) remains the same as well, with credit frictions appearing mainly as a source of additional shift terms (like the "cost-push shocks" emphasized in treatments such as those of Clarida, Gali, and Gertler, 1999). Hence some of the important conclusions of the standard literature continue to apply, at least approximately, even in an environment where credit frictions are nontrivial and time varying.

\subsection{The Robustness of Flexible Inflation (or Price-Level) Targeting}

Benigno and Woodford (2005) show that in the representative-household version of our model, optimal interest rate policy can be characterized by the requirement that interest rates be adjusted so that a certain target criterion is satisfied each period. ${ }^{25}$ To a log-linear approximation, the optimal target criterion can be expressed as

(18) $\pi_{t}+\phi\left(x_{t}-x_{t-1}\right)=0$,

regardless of the degree of steady-state distortions due to market power or distorting taxes, where $x_{t} \equiv \hat{Y}_{t}-\hat{Y}_{t}^{*}, \hat{Y}_{t}^{*}$ is a function of the exogenous disturbances to preferences, technology, fiscal policy, and markups, ${ }^{26}$ and $\phi$ is a positive coefficient. This can be viewed as a form of "flexible inflation targeting" in the sense of Svensson (1997): The acceptable near-term inflation projection should be adjusted by an amount proportional to the projected change in the output gap. (Farther in the future, there will never be continuing forecastable changes in the output gap; so the criterion will always require that the projected path of inflation a few years in the future will equal an unchanging long-run target value, here equal to zero.)

\footnotetext{
${ }^{25}$ For further discussion of targeting regimes as an approach to the conduct of monetary policy, see Svensson (1997 and 2005), Svensson and Woodford (2005), or Woodford (2007).

${ }^{26}$ In the case that the steady-state level of output under flexible prices (or with zero inflation) is efficient, $\hat{Y}_{t}^{*}$ corresponds to variations in the efficient level of output. When the steady-state level of output under flexible prices is not efficient, the two concepts differ somewhat; for the more general definition of $\hat{Y}_{t}^{*}$, and discussion of its relation to the efficient level of output and to the flexible-price equilibrium level of output, see Woodford (2009, section 2).
}

The optimal target criterion in the representative-household model can alternatively be expressed in the form

(19) $\tilde{p}_{t} \equiv p_{t}+\phi x_{t}=p^{*}$,

where $p_{t}$ is the log of the general price index at time $t$. (Note that (18) simply states that the first difference of $\tilde{p}_{t}$ should be zero each period, so that $\tilde{p}_{t}$ must never be allowed to change.) This is an output gap-adjusted price-level target, or the commitment to a rule of the form in (19), which is an example of what Hall (1984) calls an "elastic price standard." If the target criterion can be fulfilled precisely each period, the two target criteria are equivalent; but if it is not always possible for the central bank to satisfy the target criterion (as when the zero lower bound is reached, discussed below), the two commitments are no longer equivalent. In this case, there are actually advantages to the price-level formulation, as we discuss below.

Cúrdia and Woodford (2009a) show that in a special limiting case, the target criterion (18) or alternatively, (19)—continues to be necessary and sufficient for the optimality of interest rate policy, even in the model with heterogeneity and credit frictions. This is the special case in which steadystate distortions (including the steady-state credit spread $\bar{\omega}$ ) are negligible, though we allow for shocks that temporarily increase credit spreads relative to the steady-state level. Real resources used in financial intermediation are negligible (so that the shocks that increase credit spreads are purely due to an increase in the perceived fraction of bad loans), and the time-varying fraction of bad loans is independent of intermediaries' scale of operations. In this case, there are no variations in $\Xi_{t}$ and the fluctuations in $\Omega_{t}$ are essentially exogenous, so that the welfare-relevant effects of interest rate policy relate only to its effects on output and inflation, as in a model without credit frictions; and the additional terms in the aggregatesupply tradeoff (6) are purely exogenous disturbance terms, so that the derivation of the optimal target criterion proceeds as in the representativehousehold model.

More generally, the target criterion (18) will not correspond precisely to optimal policy; but our numerical investigations of calibrated models 
suggest that it can easily continue to provide a reasonably good approximation to the optimal Ramsey policy, making the prescription of "flexible inflation targeting" still a useful practical rule of thumb. Figures 7 through 10 illustrate this, for one illustrative calibration of our model, now allowing both $\Xi_{t}^{p}$ and $\omega_{t}$ to vary endogenously with the volume of private lending. ${ }^{27}$ Each figure plots the impulse responses (under a log-linear approximation to the model dynamics) of several of the endogenous variables to a particular type of exogenous disturbance, under each of four different possible specifications of monetary policy: (i) a simple "Taylor rule" using the coefficients proposed by Taylor (1993); (ii) a "strict inflationtargeting” regime, under which interest rate policy is used to ensure that inflation never deviates from its target level (zero) in response to any disturbance; (iii) a "flexible inflation-targeting" regime, under which interest rate policy ensures that (18) holds each period; and (iv) a fully optimal policy (the solution to the Ramsey policy problem).

In each of the cases shown (as well as for a large number of other types of disturbances that we have considered), the "flexible inflationtargeting" regime remains a good approximation to the fully optimal policy, even if it is no longer precisely the optimal policy. Both types of inflation-targeting regimes are closer to the optimal policy than is the Taylor rule, which mechanically responds to observed variations in real activity without taking account of the types of disturbances

\footnotetext{
${ }^{27}$ The calibration is discussed further in Cúrdia and Woodford (2009a). The model parameters that are shared with the representativehousehold version of the model are calibrated as in Woodford (2003, Chap. 6), on the basis of the empirical estimates of Rotemberg and Woodford (1997). The degree of heterogeneity of the consumption preferences of the two types is as shown in Figure 5, while the disutility of labor is the same for the two types, except for a multiplicative factor chosen so that in steady state the two types work the same amount. The steady-state credit spread is calibrated to equal 2 percent per annum, as in Mehra, Piguillem, and Prescott (2008), and is attributed entirely to the marginal resource cost of private financial intermediation, to make the endogeneity of $\Xi_{t}$ as great as possible given the average size of the spread. A highly convex function $\bar{\Xi}^{p}(L)$ is also assumed in the numerical results presented here, to make the endogeneity of the credit spread as great as possible. If we assume a less convex function for $\bar{\Xi}^{p}(L)$ or that a smaller fraction of the steady-state credit spread is due to real resource costs, then the special case in which equation (18) is optimal is an even better approximation than in the case shown in the figures.
}

responsible for those variations. ${ }^{28}$ (The Taylor rule tightens policy too much in response to increases in output resulting from productivity growth or increased government purchases, while it does not tighten enough in the case of the wage-markup shock, which causes output to fall even as inflation increases.) But especially in the case of the wage-markup shock and the shock to government purchases, the flexible inflation target provides a better approximation to optimal policy than would a strict inflation target.

The target criterion (18) continues to provide a good approximation to optimal policy in the case of a "purely financial" disturbance as well, even though such disturbances are not allowed for in the analysis of Benigno and Woodford (2005). Figure 10 shows the impulse responses to an exogenous increase in the function $\chi_{t}(L)$, corresponding to an increase in the fraction of loans expected to be bad loans, that then gradually shifts back to its steady-state value. Such a shock temporarily shifts up the value of $\bar{\omega}_{t}(L)$ for any value of $L$ and so represents a contraction of the loan supply for reasons internal to the financial sector. In equilibrium, such a disturbance results both in a contraction of private lending (and hence in equilibrium borrowing $b_{t}$, as shown in the bottomleft panel) and in an increase in the equilibrium credit spread, $\omega_{t}$ (as shown in the middle-right panel). If the central bank follows the Taylor rule, such a shock results in both an output contraction and deflation, but an optimal policy would allow little of either to occur. ${ }^{29}$ Again, the flexible

\footnotetext{
${ }^{28}$ Here we assume a rule in which the intercept term representing the equilibrium real funds rate is a constant, and the output gap is defined as output relative to a deterministic trend, as in Taylor (1993). A more sophisticated variant, in which the intercept varies with variations in the "natural rate of interest," and the output gap is defined relative to variations in the "natural rate of output" (defined as in equation (6)), provides a better approximation to optimal policy, but still less close an approximation than that provided by the flexible inflation-targeting rule. The responses to exogenous disturbances under the more sophisticated form of Taylor rule are discussed in Cúrdia and Woodford (2009b).

${ }^{29}$ Interestingly, the optimal policy does not involve a much larger cut in the policy rate than occurs under the Taylor rule. The difference is that under the Taylor rule, the central bank is unwilling to cut the policy except to the extent that this can be justified by a fall in inflation or output, and so in equilibrium those must occur; under the optimal policy, the central bank is willing to cut the policy rate without requiring inflation or output to decline, and in equilibrium they do not.
} 


\section{Figure 7}

\section{Impulse Responses to a 1 Percent Increase in Total-Factor Productivity, Under Four Alternative Monetary Policies}
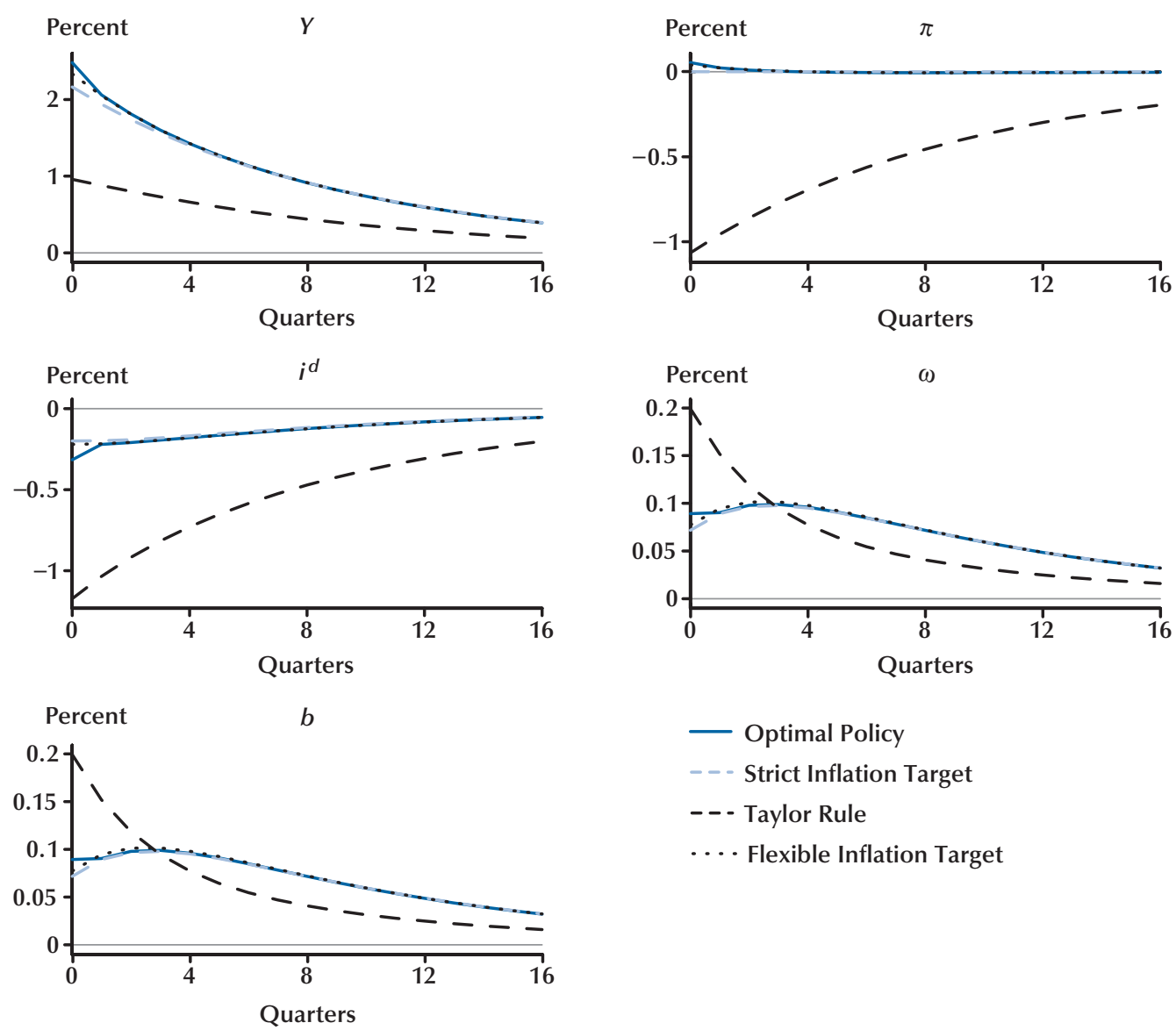

$$
\begin{aligned}
& \text { - Optimal Policy } \\
& \text { - - Strict Inflation Target } \\
& \text { - - - Taylor Rule } \\
& \text {-.. Flexible Inflation Target }
\end{aligned}
$$

SOURCE: Cúrdia and Woodford (2009a).

inflation-targeting regime provides a reasonable approximation to what would happen under an optimal policy commitment. (We obtain a very similar figure in the case in which the disturbance is instead an exogenous increase in the marginal resource cost of private financial intermediation.)

These results provide an answer to one of the questions posed in the introduction: Does keeping track of the projected paths of inflation and output alone provide a sufficient basis for judgments about whether monetary policy (by which interest rate policy is here intended) remains on track, even during times of financial turmoil?
Our results suggest that, while the target criterion (18) involving only the projected paths of inflation and the output gap is not complex enough to constitute a fully optimal policy in our extended model, ensuring that (18) holds at all times would in fact ensure that policy is not too different from a fully optimal policy commitment-not only in an environment in which financial intermediation is imperfect, but even when the main disturbances to the economy originate in the financial sector and imply large increases in the size of credit spreads.

It is important to note, however, that our results do not imply that there is no need for a 


\section{Figure 8}

\section{Impulse Responses to a 1 Percent Increase in the Wage Markup, Under Four Alternative Monetary Policies}
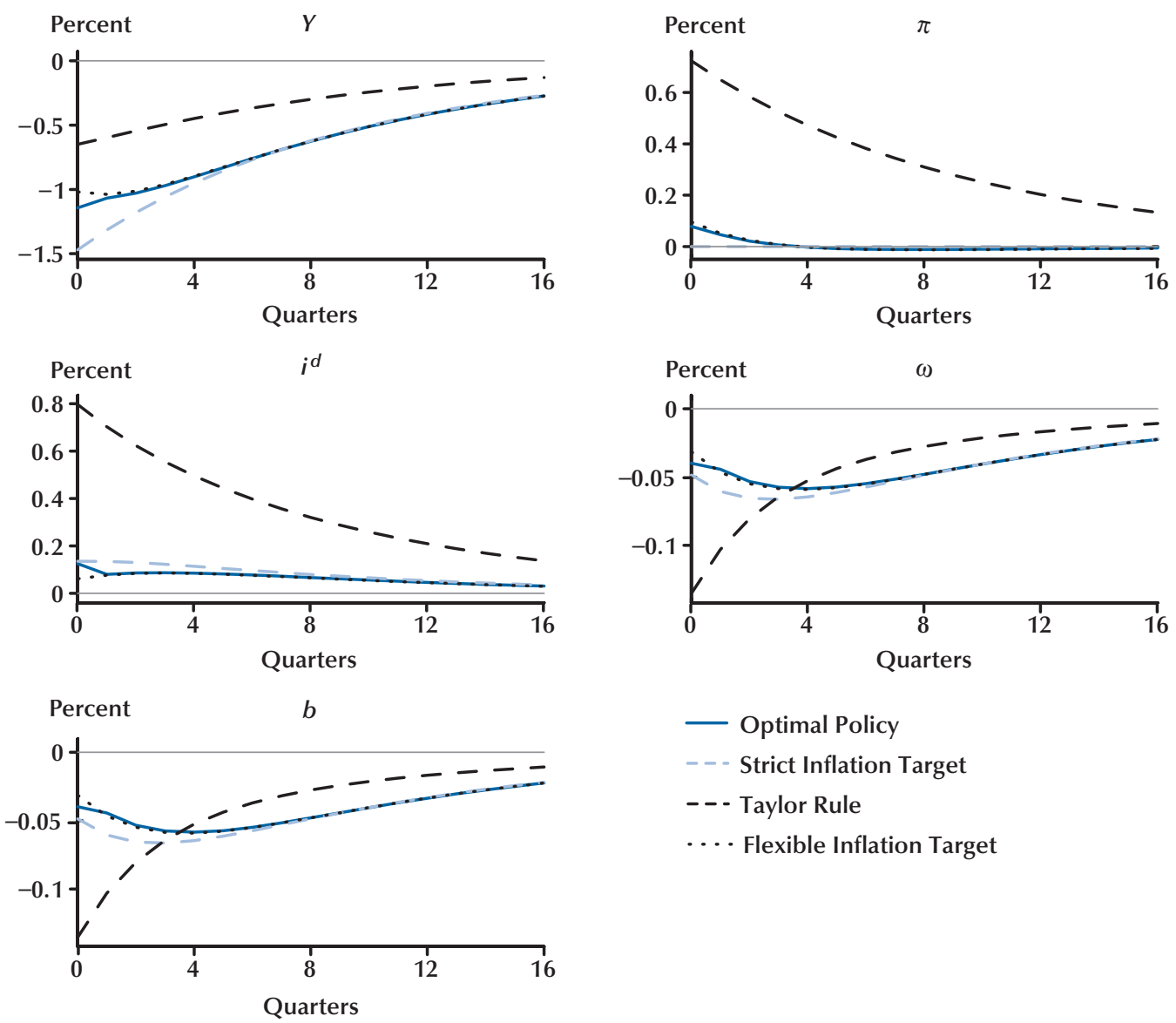

$$
\begin{aligned}
& \text { - Optimal Policy } \\
& \text { - - - Strict Inflation Target } \\
& \text { - - - Taylor Rule } \\
& \text {-... Flexible Inflation Target }
\end{aligned}
$$

SOURCE: Cúrdia and Woodford (2009a).

central bank to monitor or respond to financial conditions. Under the targeting regime recommended here, it is necessary to keep track of the various exogenous disturbances affecting the economy, to correctly forecast the evolution of inflation and output under alternative paths for the policy rate-and this includes keeping track of financial disturbances, when these are important. The simple Taylor rule, which does not require the central bank to use information about any variables other than inflation and real GDP, would not be an adequate guide to policy.

\subsection{A Spread-Adjusted Taylor Rule?}

Might a Taylor rule instead be a sufficient basis for setting interest rate policy if the standard Taylor rule is augmented, as proposed by Taylor (2008), by an adjustment for observed variations in a credit spread, such as one of the LIBOR-OIS spreads shown in Figure 1? For the kind of disturbance considered in Figure 10, this type of adjustment would allow the policy rate to be cut by more than a full percentage point even in the absence of any decline in inflation or outputwhich is exactly what is necessary to the allow 


\section{Figure 9}

\section{Impulse Responses to a 1 Percent Increase in $G_{t}$ Equal to 1 Percent of Steady-State Output, Under Four Alternative Monetary Policies}
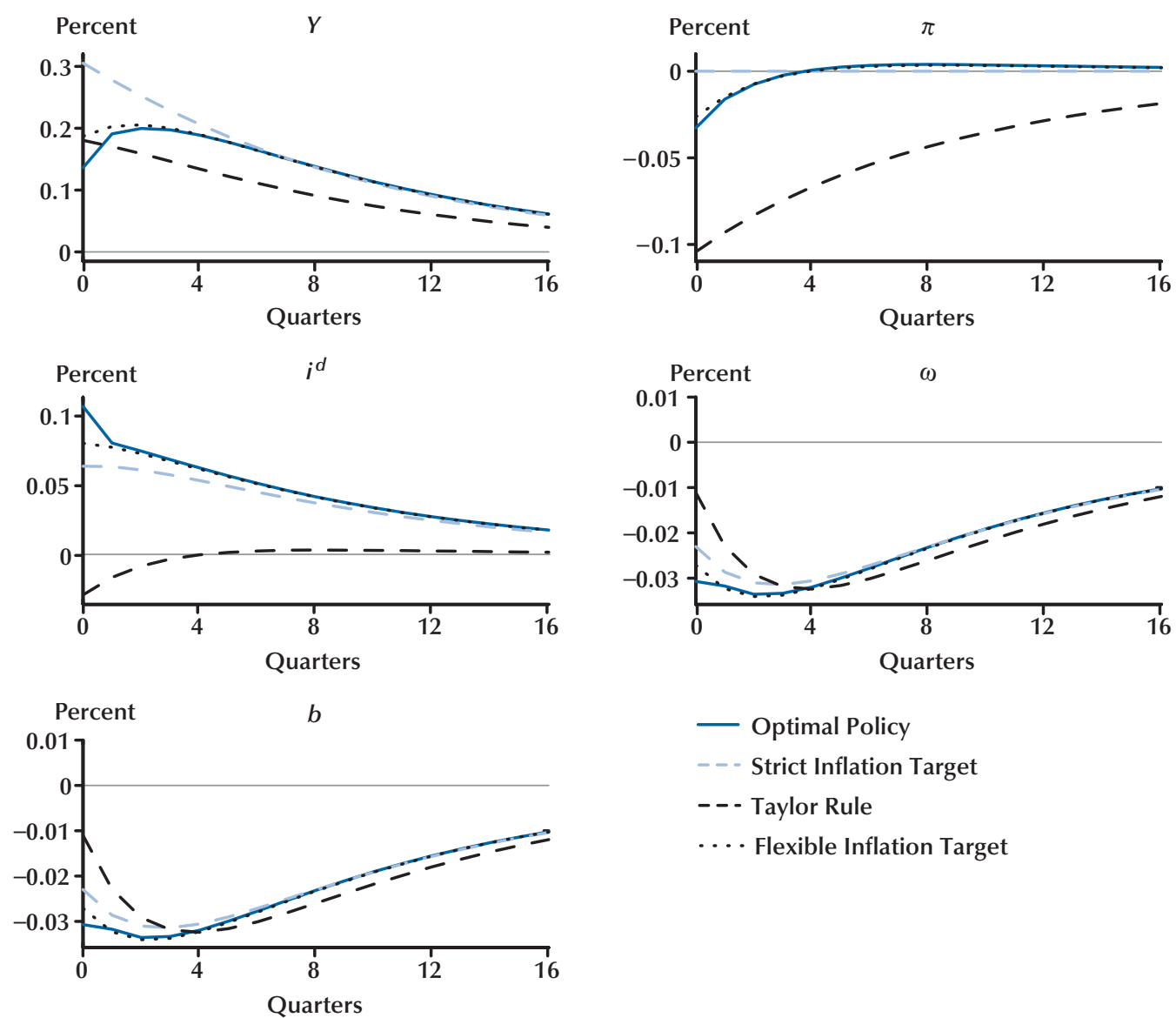

$$
\begin{aligned}
& \text { — Optimal Policy } \\
& \text { - - - Strict Inflation Target } \\
& \text { - - - Taylor Rule } \\
& \text {-.. Flexible Inflation Target }
\end{aligned}
$$

SOURCE: Cúrdia and Woodford (2009a).

the kind of equilibrium responses associated with the optimal policy commitment.

Cúrdia and Woodford (2009b) consider modified Taylor rules of this kind in the context of the same calibrated structural model used in Figures 7 through 10. While they find that the type of spread adjustment proposed by Taylor (2008) would be beneficial under some circumstances-such as the type of disturbance considered in Figure 10the desirable degree of adjustment (and even sometimes the sign of the adjustment) of the policy rate in response to a change in credit spreads is not independent of the nature of the disturbance that causes spreads to change. Even in the case of "purely financial" disturbances, like the kind considered in Figure 10, the optimal degree of response to changes in the credit spread depends on the degree of anticipated persistence of the disturbance.

In fact, the targeting regime that we propose above automatically involves a spread adjustment of the general type proposed by Taylor (2008). Given that a change in the credit spread (and in the anticipated future path of credit spreads, which determines the marginal-utility gap, $\Omega_{t}$, because of (4)) affects aggregate demand for any 


\section{Figure 10}

\section{Impulse Responses to a Shift in the Function $\chi_{t}(L)$ that Triples the Size of $\bar{\omega}_{t}(L)$ for Each Value of $L$, Under Four Alternative Monetary Policies}
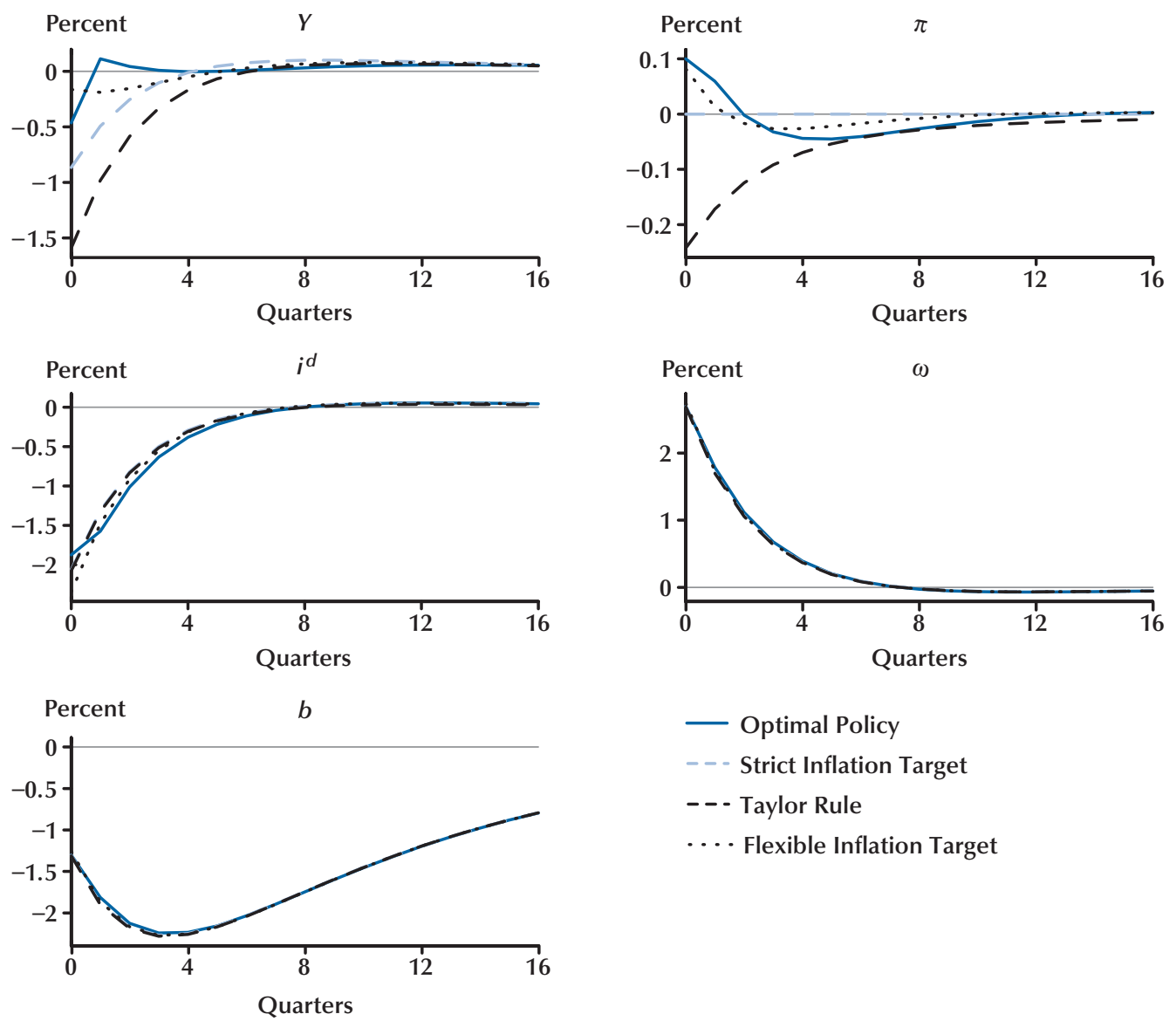

$$
\begin{aligned}
& \text { — Optimal Policy } \\
& \text { - - - Strict Inflation Target } \\
& \text { - - - Taylor Rule } \\
& \text {-... Flexible Inflation Target }
\end{aligned}
$$

SOURCE: Cúrdia and Woodford (2009a).

given anticipated path of the policy rate-both because of the difference between $i_{t}^{a v g}$ and the policy rate indicated in (5) and because of the $\hat{\Omega}_{t}$ terms in (3) - the consequences of a given path of the policy rate for the inflation and output projections will be different when the path of credit spreads changes, and so the path for the policy rate required to produce projections that conform to the target criterion will be different. Since larger credit spreads (now and in the future) reduce aggregate demand leading to lower inflation, the policy rate will generally need to be reduced to offset this effect.
Moreover, we believe that the targeting approach represents a conceptually superior way of introducing these considerations into decisions about interest rate policy. The Taylor (2008) proposal requires that one specify which particular measure of credit spreads will be taken into account in the modified reaction function. (Taylor has proposed one very specific spreadthe LIBOR-OIS spread.) But in fact central banks monitor many different credit spreads; and while in our highly stylized model there is only a single credit spread, a more empirically realistic model would have to include several (as indeed the 
FRB/U.S. model already does). Under our proposed targeting regime, each of these would be relevant to setting interest rate policy: Variations in each of the different spreads would be taken into account to the extent that they enter the equations of the model used to project the paths of inflation and output. Furthermore, under the targeting approach, the adjustment of the policy rate would not have to be a mechanical (and purely contemporaneous) function of the change in the credit spread; instead, one would automatically respond differently depending on the nature of the disturbance and would respond also to changes in the expected future path of spreads as well as to the current spread.

\subsection{Policy When the Zero Lower Bound Is Reached}

In the discussion above (and in the simulations in Figures 7 through 10), it is assumed that the zero lower bound on the policy rate is never reached, and our theoretical model implies that it should not be reached, in the case of small enough shocks. But it is theoretically possible for it to bind in the case of large-enough shocks of certain types, and recent events in the United States and elsewhere have shown that one cannot presume that the constraint will never bind in practice. (As a practical matter, it seems that it is most likely to bind following severe disruptions of the financial sector, as in the case of the Great Depression, in Japan during the 1990s, and at present.)

When the zero bound is a binding constraint, it may not be possible for the central bank to use interest rate policy to ensure fulfillment of the target criterion (19) in all periods. Does this affect the validity of our recommendation of this policy? Although it may not be possible to fulfill the target criterion at all times, that does not in itself imply that it is not desirable to adjust interest rate policy to fulfill the criterion when it can be satisfied. Also, nothing here implies that, when policymakers deliberate interest rate policy, they should forgo the question of whether there exists an interest rate path that would satisfy the target criterion.
But the fact that the lower bound is sometimes a binding constraint also has consequences for the appropriate policy target even under certain circumstances when the zero lower bound would not prevent one from achieving the target criterion (18). The reason is that the severity of the distortions during the period when the lower bound is binding should depend on the way in which policy is expected to be conducted after the constraint ceases to bind. Hence, the policy that a central bank should commit to follow in such a period should be chosen with a view to the consequences of the anticipation of that policy during the period when the zero bound binds.

Eggertsson and Woodford (2003) analyze this issue in a model that is equivalent to a special case of the model considered here. Let us again consider the special case (mentioned in Section 3.1) in which there are no steady-state distortions, no resources are used in financial intermediation, and the fraction of bad loans is independent of the scale of lending. Because in this case both the credit spread and the marginal-utility gap evolve exogenously, a second-order Taylor series approximation to the objective function (14), expanding around the optimal (zero-inflation) steady state, is exactly the same quadratic function of inflation and the output gap as in the case of a representative-household model (the case considered by Eggertsson and Woodford). The "intertemporal IS relation" (3) and the aggregate-supply relation (6) are also identical to those of the representativehousehold model, except for the presence of additional additive disturbance terms involving $\hat{\omega}_{t}$ and $\hat{\Omega}_{t}$.

The optimal policy problem-which can be stated as the choice of processes for inflation, output, and the policy rate consistent with (3), (6), and (13) each period to maximize the welfare measure written in terms of output and inflation-is of the same form as the one analyzed by Eggertsson and Woodford (2003), except with additional possible interpretations of the exogenous disturbance terms. In particular, the extension of the model to incorporate credit frictions provides a more empirically realistic interpretation of the disturbance hypothesized by Eggertsson and Woodford (2003), which makes the real policy 


\section{Figure 11}

\section{Equilibrium Responses of the Policy Rate, Inflation, and the Output Gap, Under Two Alternative Monetary Policies}
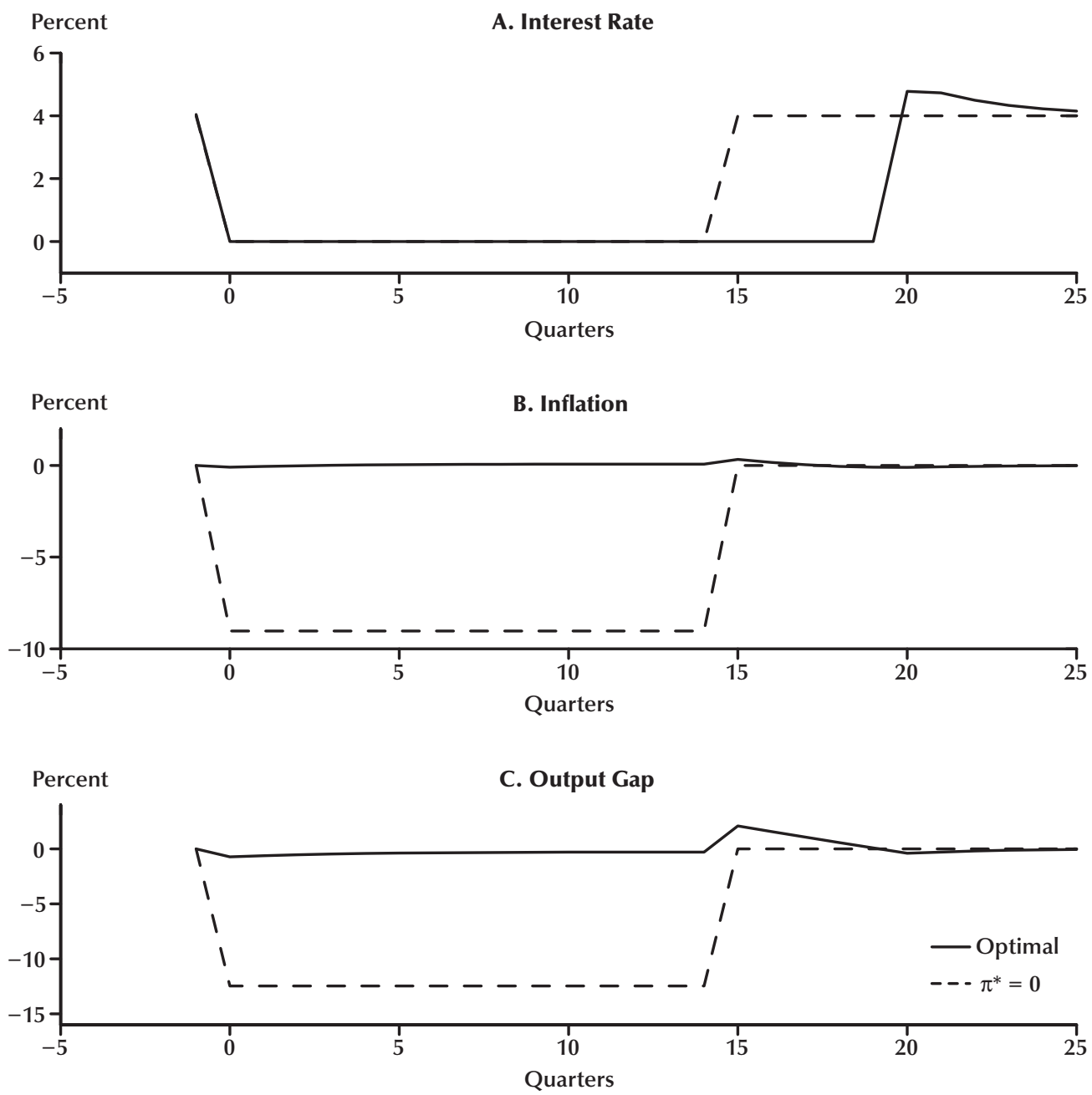

NOTE: The figure represents equilibrium responses when the expected probability of loan default exogenously increases beginning in quarter zero and ending in quarter 15.

SOURCE: Eggertsson and Woodford (2003).

rate needed to maintain a constant zero output gap temporarily negative. Rather than postulate a sudden, temporary disappearance of real spending opportunities or a temporary reduction in the rate of time preference, we can instead attribute the situation to a temporary increase in credit spreads as a result of disruption of the financial sector.
Eggertsson and Woodford (2003) show that it can be a serious mistake for a central bank to be expected to return immediately to the pursuit of its normal policy target as soon as the zero bound no longer prevents it from hitting that target. For example, Figure 11 (reproduced from their paper) compares the dynamic paths of the policy rate, the inflation rate, and aggregate output under two 


\section{Cúrdia and Woodford}

alternative monetary policies in the case of a real disturbance (here interpreted as an exogenous increase in the probability that loans are bad, requiring intermediaries to increase the credit spread by several percentage points) that begins in period zero and lasts for 15 quarters, before real fundamentals permanently return to their original ("normal") state.

In this case, if the financial disturbance were never to occur, optimal policy would involve maintaining a zero inflation rate, as this would also imply a zero output gap in every period. After the disturbance dissipates, one of the feasible policies is an immediate return to this zero-inflation steady state (under the parameterization assumed in the figure, this involves a nominal interest rate of 4 percent), and this is optimal from the point of view of welfare in all periods after the financial disturbance dissipates. It is not, however, possible to maintain the zero-inflation steady state at all times, because during the financial disturbance this would require the policy rate to equal -2 percent, which would violate the zero lower bound.

One of the policies considered in Figure 10 (dashed lines) is strict (forward-looking) inflation targeting: The central bank uses interest rate policy to maintain a zero inflation rate whenever it is not prevented by the zero lower bound on the policy rate. When undershooting the inflation target cannot be avoided, the policy rate is maintained at the lower bound. The other policy (solid lines) is the optimal Ramsey policy, when the zero lower bound is included among the constraints on the set of possible equilibria. The forwardlooking inflation-targeting policy is clearly much worse, as it involves both a much more severe output contraction and much more severe deflation during the period when the zero bound constrains policy.

The problem with the forward-looking inflation-targeting policy is that because the central bank simply targets zero inflation from the time that it again becomes possible to do so, all of the deflation that occurs while the zero bound binds is fully accommodated by the subsequent policy: The central bank continues to maintain the price level at whatever level it has fallen to. This results in expected deflation during the entire period of the financial disturbance, for deflation will continue as long as the financial disruption continues, while no inflation will be allowed even if the disturbance dissipates; this expected deflation makes the zero bound on nominal interest rates a higher lower bound on the real policy rate, making the contraction and deflation worse, giving people reason to expect more deflation as long as the disruption continues, and so on in a vicious circle.

The outcome would be even worse if the central bank were to seek to achieve the target criterion (18) each period as soon as it becomes possible to do so. This is because, once credit spreads contract again, this policy would require the central bank to target negative inflation and/or a negative output gap (even though zero inflation and a zero output gap would now be achievable), simply because there had been a large negative output gap in the recent past (when the zero bound was a binding constraint); but the expectation of such policy would make the output contraction while the zero bound constrained policy even more severe (justifying even tighter policy immediately following the "exit" from the "liquidity trap," and so on).

Under the optimal policy, there is instead a commitment to maintain accommodative conditions for a brief interval, even though the reduction in credit spreads means that this level for the policy rate is now expansionary, leading to a mild boom and temporary inflation above the long-run target level (of zero). The expectation that this will occur during the "exit" from the trap results in much less contraction of economic activity and much less deflation, because it makes the perceived real rate of interest lower at all times while the policy rate is at zero (given that there is in each period some probability that credit spreads will shrink again in the next period, allowing mild inflation to occur). This expectation results in less deflation and higher real activity while the lower bound binds; and the expectation that continuation of the financial stress will have less drastic consequences is itself a substantial factor in making those consequences much less drastic-in a "virtuous circle" that exactly reverses the logic of our analysis above. 
While our analysis implies that it is desirable for people to be able to expect that the "exit" from the trap will involve mild inflation, it does not follow that the possibility of occasionally hitting the zero lower bound on the policy rate is a reason to aim for a substantial positive rate of inflation at all times (as proposed by Summers, 1991) simply to ensure that a zero nominal interest rate will always mean a sufficiently negative value of the real policy rate. To the extent that a historydependent inflation target of the kind called for in Eggertsson and Woodford (2003) can be made credible and understood by the public, it suffices that the central bank be committed to bringing about a temporarily higher rate of inflation only on the particular occasions when the zero lower bound has bound in the recent past, and not all of the time. ${ }^{30}$

This analysis implies that a commitment to maintain policy accommodation can play an important role in mitigating the effects of the zero lower bound on interest rates. One might reasonably ask for what length of time it is sensible to commit to keep rates low, and in particular whether it is really prudent to make any lengthy commitment when it is hard for a central bank to be certain that recovery may not come much sooner than anticipated. The answer is that the best way to formulate such a commitment is not in terms of a period of time that can be identified with certainty in advance, but rather in terms of targets that must be met for the removal of policy accommodation to be appropriate.

In fact, Eggertsson and Woodford (2003) show that in the representative-household model (and hence similarly in the special case described above), optimal policy can be precisely described, regardless of the nature of the exogenous disturbances, ${ }^{31}$ by a target criterion involving only the path of the output gap-adjusted price level

\footnotetext{
${ }^{30}$ Eggertsson and Woodford (2003) compare the welfare levels associated with alternative constant inflation targets and find that the existence of an occasionally binding zero lower bound does indeed make the optimal inflation target higher than it would otherwise be, if one must choose from among this very restrictive class of policies. But they show that even the best policy in that class involves much larger average distortions than a price-level targeting policy, even though a price-level targeting policy implies a long-run average inflation rate of zero.
}

defined in (18). Under the optimal rule, the central bank has a target each period for $\tilde{p}_{t}$ that depends only on the economy's history through period $t-1$ and must use interest rate policy to achieve the target, if this is possible without violation of the zero lower bound; if the target is undershot even with a zero policy rate, the policy rate is at any rate reduced to zero-and the target for $\tilde{p}_{t-1}$ is increased in proportion to the degree of undershooting. In periods when the zero bound does not bind, the target for the gap-adjusted price level is not adjusted, and the target criterion is the same as the one discussed in Section 3.1.

Actually, the adjustments of the target are not of great importance, even when the zero bound does bind: Eggertsson and Woodford (2003) show that almost all of the improvement in stabilization achievable under the optimal policy commitment can be obtained by simply committing to a target criterion of the form in (19) with a constant target $p^{*}$. The crucial feature of the optimal policy is that the target for $\tilde{p}_{t}$ must not be allowed to fall as a result of having undershot the target in past periods. Hence one of the approximate characterizations of optimal policy proposed in Section 3.1 continues to provide a good approximation to optimal policy even when the zero lower bound sometimes binds: It is simply important that the commitment be to the level form of the target criterion (19) rather than to the growth rate form (18).

\section{OPTIMAL POLICY: CREDIT POLICY}

We turn now to the final of our three independent dimensions of central bank policy, namely, adjustment of the composition of the asset side of the central bank's balance sheet, taking as given the overall size of the balance sheet (deter-

\footnotetext{
${ }^{31}$ Their analysis allows for both exogenous variations in the "natural rate of interest" (which means an additive exogenous term in the intertemporal IS relation) and in the "cost-push" term (which means an additive exogenous term in the Phillips-curve tradeoff), evolving according to arbitrary stochastic processes. Since the effects of the financial frictions in (3) and (6) are to add additional terms involving $\hat{\Omega}_{t}$ that can be viewed as a combination of these two types of shifts, the optimal target criterion derived by Eggertsson and Woodford (2003) continues to apply-under the special assumptions stated above-even in the presence of time-varying credit frictions.
} 


\section{Cúrdia and Woodford}

mined by the reserve-supply decision discussed in Section 2). According to the traditional doctrine of "Treasuries only," the central bank should not vary the composition of its balance sheet as a policy tool. Instead, it should avoid both balancesheet risk and the danger of politicization by holding only (essentially riskless) Treasury securities at all times, while varying the size of its balance sheet to achieve its stabilization goals for the aggregate economy. ${ }^{32}$

Apart from these prudential concerns, if private financial markets can be relied on to allocate capital efficiently, it is hard to argue that there would be any substantial value to allowing the central bank this additional dimension of policy. Eggertsson and Woodford (2003) present a formal irrelevance proposition in the context of a representative-household general-equilibrium model. In their model, the assets purchased by the central bank have no consequences for the equilibrium evolution of output, inflation, or asset pricesand this is true regardless of whether the central bank purchases long-term or short-term assets, nominal or real assets, riskless or risky assets, and so on. In addition, even in a model with heterogeneity of the kind considered here, the composition of the central bank's balance sheet would be irrelevant if we were to assume frictionless private financial intermediation, since private intermediaries would be willing to adjust their portfolios to perfectly offset any changes in the portfolio of the central bank.

This irrelevance result does not hold, however, in the presence of credit frictions of the kind assumed in Section 1; so we can also consider the optimal use of this additional dimension of policy if we are willing to suppose that the prudential arguments against the central bank's involvement in the allocation of credit should not be determinative, at least in the case of sufficiently severe financial disruptions. In our model, an increase in $L_{t}^{c b}$ can improve welfare on two grounds: For a given volume of private borrowing, $b_{t}$ an increase in $L_{t}^{c b}$ allows the volume of private lending, $L_{t}$, to fall, which should reduce both the

\footnotetext{
${ }^{32}$ See Goodfriend (2009) for a discussion of this view and a warning about the dangers of departing from it.
}

resources $\Xi_{t}^{p}$ consumed by the intermediary sector and the equilibrium credit spread, $\omega_{t}$ (due to equilibrium (7)). Under plausible conditions, our model implies both a positive shadow value $\varphi_{\Xi, t}$ of reductions in $\Xi_{t}$ (the Lagrange multiplier associated with the resource constraint (2)) and a positive shadow value $\varphi_{\omega, t}$ of reductions in $\omega_{t}$ (the Lagrange multiplier associated with the constraint (4)); hence an increase in $L_{t}^{c b}$ should be desirable on both grounds.

In the absence of any assumed cost of central bank credit policy, one can easily obtain the result that it is always optimal for the central bank to lend an amount sufficient to allow an equilibrium with $L_{t}=0$; that is, the central bank should substitute for private credit markets altogether. Of course, we do not regard this as a realistic conclusion. As a simple way of introducing into our calculations the fact that the central bank is unlikely to have a comparative advantage at the activity of credit allocation under normal circumstances, we assume that central bank lending consumes real resources in a quantity $\Xi^{c b}\left(L_{t}^{c b}\right)$, by analogy with our assumption that real resources, $\Xi_{t}^{p}$, are consumed by private intermediaries. The function $\Xi^{c b}(L)$ is assumed to be increasing and at least weakly convex; in particular, we assume that $\Xi^{c b^{\prime}}(0)>0$ so that there is a positive marginal resource cost of this activity, even when the central bank starts from a balance sheet made up entirely of Treasury securities.

\subsection{When Is Active Credit Policy Justified?}

The first-order conditions for optimal choice of $L_{t}^{c b}$ then become

$$
\begin{aligned}
& \varphi_{\Xi, t}\left[\bar{\Xi}_{t}^{p^{\prime}}\left(b_{t}-L_{t}^{c b}\right)-\Xi^{c b^{\prime}}\left(L_{t}^{c b}\right)\right] \\
& +\varphi_{\omega, t}\left[\bar{\Xi}_{t}^{p \prime}\left(b_{t}-L_{t}^{c b}\right)+\chi_{t}^{\prime \prime}\left(b_{t}-L_{t}^{c b}\right)\right] \leq 0,
\end{aligned}
$$

(21) $L_{t}^{c b} \geq 0$,

together with the complementary slackness condition that at least one of conditions (20) or (21) must hold with equality in each period. (Here, the first expression in square brackets in (20) is the partial derivative of $\Xi_{t}$ with respect to $L_{t}^{c b}$, hold- 
ing constant the value of total borrowing, $b_{t}$; the second expression in square brackets is the partial derivative of $\omega_{t}$ with respect to $L_{t}^{c b}$ under the same assumption.)

A "Treasuries only" policy is optimal in the event of a corner solution, in which (20) is an inequality, as will be the case if $\Xi^{c b^{\prime}}(0)$ is large enough. In our view, it is probably most reasonable to calibrate the model so that this is true in steady state. Then not only will the optimal policy involve "Treasuries only" in the steady state, but (assuming that the inequality is strict at the steady state) this will continue to be true in the case of any stochastic disturbances that are small enough. However, it will remain possible for the optimal policy to require $L_{t}^{c b}>0$ in the case of certain large-enough disturbances. This is especially likely to be true in the case of large-enough disruptions of the financial sector of a type that increase the marginal resource cost of private intermediation (the value of $\bar{\Xi}^{p^{\prime}}$ ) and/or the degree to which increases in private credit require a larger credit spread (the value of $\bar{\omega}^{\prime}$ ).

However, not all "purely financial" disturbances-by which we mean exogenous shifts in the functions $\bar{\Xi}_{t}^{p}(L)$ or $\chi_{t}(L)$ of a type that increase the equilibrium credit spread $\bar{\omega}_{t}(L)$ for a given volume of private credit-are equally likely to justify an active central bank credit policy on the grounds just mentioned. ${ }^{33}$ To illustrate this, let us consider four different possible purely financial disturbances, each of which will be assumed to increase the value of $\bar{\omega}_{t}(\bar{L})$ by the same number of percentage points. Here, by an additive shock, we mean one that translates the schedule $\bar{\omega}_{t}(L)$ vertically by a constant amount; a multiplicative shock will instead multiply the entire schedule $\bar{\omega}_{t}(L)$ by some constant factor greater than 1 . We shall also distinguish between disturbances that change the function $\bar{\Xi}_{t}(L)$ (" $\Xi$ shocks") and disturbances that change the function $\chi_{t}(L)$ (" $\chi$ shocks"). Thus a "multiplicative $\chi$ shock" is a change in the

\footnotetext{
${ }^{33}$ Our result here is quite different from that in Section 3, where the consequence of a "purely financial" disturbance for optimal interest rate policy, taking as given the path of central bank lending to the private sector, depends (to a first approximation) only on the size of the shift in $\bar{\omega}_{t}(\bar{L})$, which is why we do not bother to show the optimal responses to more than one type of purely financial disturbance.
}

function $\chi_{t}(L)$; as a consequence, of which the schedule $\bar{\omega}_{t}(L)$ is multiplied by a factor greater than 1 for all values of $L$, and so on.

With the model calibrated as in the numerical exercises in Figures 7 through 10, Figure 12 plots the dynamic response of the sum of the three positive terms on the left-hand side of (20) to each of these four types of purely financial disturbances. In these simulations, both interest rate policy and reserve-supply policy are assumed to be optimal, as discussed in Sections 2 and 3. We assume in each case that there is no central bank lending to the private sector in the equilibrium being computed, but we ask (in the equilibrium computed under this assumption) what the smallest value of $\Xi^{c b^{\prime}}(0)$ is at each point in time, for which this would be consistent with the first-order condition (21). (Thus an increase in the quantity plotted means that the marginal benefit of central bank credit policy is increased, even if in our calculations no central bank lending actually occurs.) We divide the sum of the three terms by the value of $\varphi_{\Xi, t}$, so that the quantity plotted is precisely the threshold value of $\Xi^{c b^{\prime}}(0)$, expressed in terms of an interest rate spread. (Since it is an interest rate spread, we multiply by 4 so that the quantity on the vertical axis of the figure is in units of percentage points per annum.) In the figure, each of the four disturbances is of a size that increases the value of $\bar{\omega}_{t}(\bar{L})$ by 4 percentage points per annum (i.e., from 2.0 percent to 6.0 percent).

In the absence of any disturbances, the steadystate value of this quantity is a little less than 3.5 percentage points per annum. This means that a marginal resource cost of central bank loan origination of 3.5 percent or higher will suffice to justify our proposal above-that in the steady state the optimal quantity of central bank credit is zero. ${ }^{34}$ Let us suppose that $\Xi^{c b^{\prime}}(0)$ is equal to 4.0 percent. Then in the absence of shocks, a corner solution with Treasuries only is optimal. However, either a "multiplicative $\Xi$ shock" or an "additive $\Xi$ shock" of the size assumed would

\footnotetext{
${ }^{34}$ Note that this quantity is well above the marginal resource cost of private lending in the steady state, which we have calibrated at 2.0 percent per annum because our baseline calibration implies a relatively inelastic private supply of credit: $\bar{\omega}_{t}(L)$ is steeply increasing with $L$.
} 
Figure 12

\section{Response of the Critical Threshold Value of $\Xi^{c b^{\prime}(0)}$ for a Corner Solution, Under Four "Purely Financial" Disturbances}

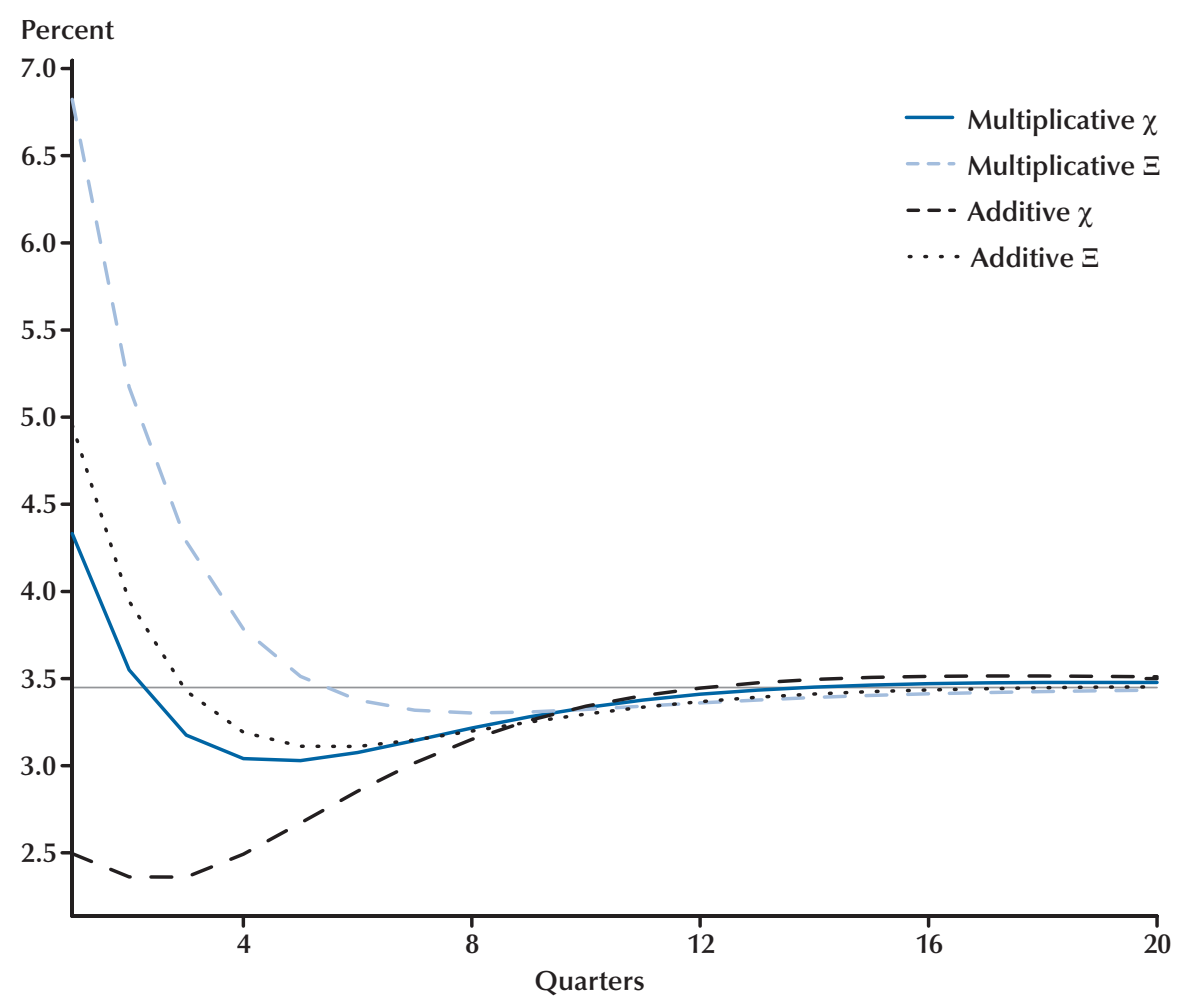

NOTE: For each disturbance, $\bar{\omega}_{t}(\bar{L})$ increases by 4 percentage points.

cause condition (21) to be violated in the case of a corner solution; hence optimal policy would require a positive quantity of central bank lending. (In the case of the "multiplicative $\Xi$ shock," this would be true even if $\Xi^{c b^{\prime}}(0)$ were equal to 5.0 percentage points.)

On the other hand, even in the case of the "multiplicative $\Xi$ shock," the threshold required to justify a corner solution is only above 4 percent in the quarter of the shock and the quarter immediately following it-despite the fact that in our numerical experiment the disturbance is assumed to have an autocorrelation coefficient of 0.9 , so that the shift in the $\bar{\omega}_{t}(L)$ schedule is still 65 percent of its initial magnitude a year later. This suggests that, even in the case of those disturbances for which the welfare benefits of central bank credit policy are greatest, departure from the corner solution is likely to be justified only for a relatively brief period of time.

\subsection{An Example with Active Credit Policy}

As an example of how optimal credit policy can, under some circumstances, substantially alter the economy's response to a financial disruption, Figure 13 considers the optimal response to a "multiplicative $\Xi$ shock," under a calibration in which $\Xi^{c b^{\prime}}(0)$ is assumed to be low enough so that even in the steady state a corner solution is not optimal. ${ }^{35}$ (While this is not the case that we regard as most realistic, it simplifies the calcula-

\footnotetext{
${ }^{35}$ This alternative calibration is chosen to imply that in the steady state, only 5 percent of total credit, $b_{t}$, is supplied by the central bank.
} 


\section{Figure 13}

\section{Impulse Responses to a Shift in $\bar{\Xi}_{t}(L)$ that Triples the Size of $\bar{\omega}_{t}(L)$ for Each Value of $L$, Under Optimal Interest Rate Policy and Two Alternative Assumptions About Credit Policy}
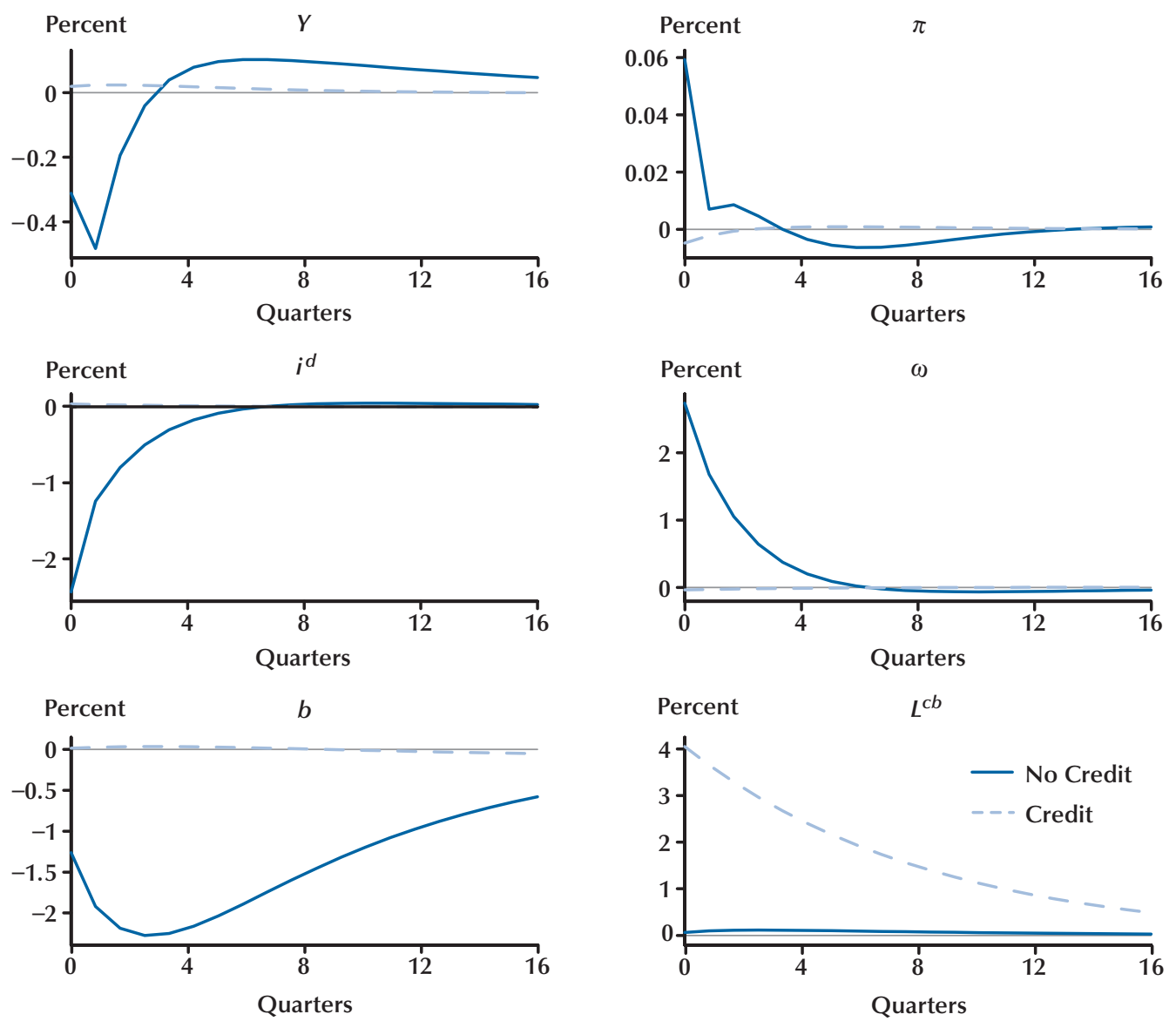

tions reported in Figure 13, since it implies that constraint (21) never binds. We leave for future work analysis of the more interesting case, in which (21) binds in some periods and not in others.) The figure plots the impulse responses under two alternative assumptions about policy: With credit, central bank policy is optimal along all three dimensions (and $L_{t}^{c b}$ varies over time); with no credit, $L_{t}^{c b}$ is constrained to equal the steady-state value $\bar{L}^{c b}$ at all times, ${ }^{36}$ while interestrate policy and reserve-supply policy are optimal.

\footnotetext{
${ }^{36}$ We impose the constraint that $L_{t}^{c b}$ must equal $\bar{L}^{c b}$, rather than zero, in the no-credit case, so that the steady state is the same under both policies.
}

In addition to the responses of the five variables plotted in Figures 7 through 10, Figure 13 also plots the response of an additional variable, $\hat{L}_{t}^{c b}$, indicating the deviation of central bank credit from its steady-state value, expressed as a fraction of total steady-state credit, $\bar{b}$ (in percentage points).

Under an optimal use of credit policy, central bank lending to the private-sector increases substantially in response to the financial disturbance (central bank lending increases from 5 percent of total credit to a little over 9 percent). As a result, the large increase in the credit spread that would otherwise occur as a result of the shock is essen- 


\section{Cúrdia and Woodford}

tially prevented from occurring (so that the credit spread remains close to its steady-state level of 2.0 percent per annum). As a further consequence, it is not necessary under this policy to cut the policy rate sharply, as would otherwise be required by an optimal interest rate policy. The substantial contraction of credit that would otherwise occur (an eventual contraction of aggregate credit by more than 2 percent a year after the shock) is largely avoided, and the modest effects on output and inflation that would occur even under an optimal interest rate policy in the absence of an active credit policy are also largely avoided.

This example indicates that, under at least some circumstances, our model would support a fairly aggressive use of active credit policy for stabilization purposes. We must caution, however, that these results are quite dependent upon assumptions about the nature of the financial disturbance. It is equally possible to conclude that central bank credit should be contracted (assuming that it would be positive to begin with) in response to a disturbance that increases credit spreads. If the only form of purely financial disturbance is an "additive $\chi$ disturbance," and we assume that $\Xi^{c b}\left(L^{c b}\right)$ is a linear function, then none of the functions $\bar{\Xi}^{p^{\prime}}(L), \bar{\Xi}^{p^{\prime \prime}}(L)$, or $\chi^{\prime}(L)$ is time varying and $\Xi^{c b^{\prime}}$ is a constant. In this case, the requirement that (20) hold with equality determines the volume of private credit, $L_{t}$, as a timeinvariant function of $\varphi_{\omega, t} / \varphi_{\Xi, t}$. In the case of a disturbance that increases the credit spread, the resulting decline in credit demand, $b_{t}$, means that, for credit supply $L_{t}$ to be stabilized, $L_{t}^{c b}$ would have to contract; so unless $\varphi_{\omega, t} / \varphi_{\Xi, t}$ changes to such an extent that the value of $L_{t}$ consistent with (20) falls as much as $b_{t}$ does, ${ }^{37}$ it is optimal for $L_{t}^{c b}$ to contract (as Figure 12 would also suggest). In a case of this kind, active credit policy would actually cause credit to contract by more (and credit spreads to increase by more) than they would if the supply of central bank credit did not respond to the shock. ${ }^{37}$ Our numerical experiments indicate that this can easily fail to be
the case.

\subsection{Segmented Credit Markets}

In the simple model expounded above, there is a single credit market and single borrowing rate, $i_{t}^{b}$, charged for loans in this market. Our discussion of central bank credit policy has correspondingly simply referred to the optimal quantity of central bank lending to the private sector overall, as if the allocation of this credit is not an issue. In reality, of course, there are many distinct credit markets and many different parties to which the central bank might consider lending. Moreover, since there is only a potential case to be made for central bank credit policy when private financial markets are severely impaired, it does not make sense to assume efficient allocation of credit among different classes of borrowers by the private sector, so that only the total credit extended by the central bank would matter. Our simple discussion here has sought merely to clarify the connection that exists, in principle, between decisions about credit policy and the other dimensions of credit policy. An analysis of credit policy that could actually be used as a basis for credit policy decisions would instead need to allow for multiple credit markets, with imperfect arbitrage between them.

We do not here attempt an extension of our model in that direction. (A simple extension would be to allow for multiple types of "type $b$ " households, each only able to borrow in a particular market with its own borrowing rate and market-specific frictions for the intermediaries lending in each of these markets.) We shall simply note that in such an extension there would be a distinct first-order condition, analogous to conditions (20) and (21), for each of the segmented credit markets. There would be no reason to assume that the question of whether active credit policy is justified should have a single answer at a given point in time: Lending might be justified in one or two specific markets while the corner solution remained optimal in the other markets.

The conditions that should be appealed to in order to justify central bank lending are more microeconomic than macroeconomic: They relate to the severity of the distortions that have arisen in particular markets and to the costs of intervention in those particular markets, rather than to 
aggregate conditions. Thus the main determinants of whether central bank credit policy is justifiedwhen it is justifiable to initiate active policy and when it would be correct to phase out such programs-should not be questions such as whether the zero lower bound on interest rate policy binds or whether the central bank continues to undershoot the level of real GDP that it would like to attain. While aggregate conditions will be one factor that affects the shadow value of marginal reductions in the size of credit spreads (represented by the multiplier $\varphi_{\omega, t}$ in (20)), the value of this multiplier will likely be different for different markets and the main determinants of variations in it are likely to be market specific. This will apply even more to the other variables that enter into the first-order condition (20).

Hence it would be a mistake to think of credit policy as a substitute for interest rate policy, an alternative tool that can be used to achieve the same goals and that should be used to achieve the central bank's target criterion for inflation and the output gap when interest rate policy alone is unable to. Such a concept would be dangerous for two reasons. On the one hand, it would direct attention away from the most relevant costs and benefits when thinking about the appropriate scale, timing, and allocation of active credit policy. And on the other hand, it could also allow the central bank to avoid recognition of the extent to which the correct target criterion for interest rate policy needs to be modified as a result of the zero lower bound-in particular, to avoid the challenge of shaping expectations about interest rate policy after the lower bound ceases to bind, on the ground that credit policy (or "quantitative easing") should allow the bank's usual target criterion to be achieved continuously, without any need for signaling about unconventional future interest rate policy as compensation for past target misses.

\section{CONCLUSIONS}

We have shown that a canonical New Keynesian model of the monetary transmission mechanism can be extended in a fairly simple way to allow analysis of additional dimensions of central bank policy that have been at center stage during the recent global financial crisisvariations in the size and composition of the central bank balance sheet and in the interest rate paid on reserves-alongside the traditional monetary policy issue of the choice of an operating target for the federal funds rate (or some similar overnight inter-bank rate elsewhere). We have also considered the consequences for monetary policy analysis both of nonzero credit spreads all of the time and of financial disruptions that greatly increase the size of those spreads for a period of time; we have also considered the consequences of the fact the zero lower bound for short-term nominal interest rates is sometimes a binding constraint on interest rate policy.

One of our most important conclusions is that these issues can be addressed in a framework that represents a straightforward extension of the kind of model often used for monetary policy analysis in the past. This allows both the considerations emphasized in the traditional literature and the more novel considerations brought to the fore by recent events to be taken into account, within a single coherent framework. This integration is particularly important, in our view, for clear thinking about the way in which the transition from the current emergency policy regime to a more customary policy framework should be handled as financial conditions normalize. Because of the importance of expectations regarding future policy in determining market outcomes now, we believe that clarity about "exit strategy" is important for the success of policy even during periods of severe disruption of financial markets.

Another important implication of our model is that interest rate policy should continue to be a central focus of monetary policy deliberations, despite the existence of the other dimensions of policy discussed here, and despite the existence of time-varying credit frictions that complicate the relationship between the central bank's policy rate and financial conditions more broadly. While welfare can also be affected by reserve-supply policy, we argue that this dimension of policy should be determined by a simple principle that does not require any discretionary adjustments in light of changing economic conditions: Inter- 


\section{Cúrdia and Woodford}

mediaries should be satiated in reserves at all times, by maintaining an interest rate on reserves at or close to the current target for the policy rate.

And while welfare can similarly be affected by central bank credit policy, to the extent that nontrivial credit frictions exist, we nonetheless believe that under normal circumstances a corner solution ("Treasuries only") is likely to represent the optimal composition of the central bank balance sheet. Decisions about active credit policy then will be necessary only under relatively unusual circumstances, and it will be desirable to phase out special credit programs relatively rapidly after the disturbances that have justified their introduction. We thus do not anticipate that it should be necessary to routinely make statecontingent adjustments of central bank policy along multiple dimensions, even if recent events suggest that it is desirable for central banks to have the power to act along additional dimensions under sufficiently exigent circumstances.

Finally, our results suggest that the traditional emphasis in interest rate policy deliberations on the consequences of monetary policy for the projected evolution of inflation and aggregate real activity is not mistaken, even taking into account the consequences for the monetary transmission mechanism of time-varying credit frictions. At least in the context of the simple model of credit frictions proposed here, optimal interest rate policy can be characterized to a reasonable degree of approximation by a target criterion that involves the paths of inflation and of an appropriately defined output gap, but no other endogenous target variables. This does not mean that central banks should remain indifferent toward changes in financial conditions; to the contrary, credit spreads (and perhaps other measures of financial market distortions as well) should be closely monitored and taken into account in judging the forward path of interest rate policy necessary for conformity with the target criterion. However, financial variables need not be taken themselves as targets of monetary policy.

The main respect in which the appropriate target criterion for interest rate policy should be modified to take account of the possibility of financial disruptions is by aiming at a target path for the price level (ideally, for an output gap-adjusted price level), rather than for a target rate of inflation looking forward, as a forward-looking inflation target accommodates a permanent decline in the price level after a period of one-sided target misses due to a binding zero lower bound on interest rates. Our analysis implies that a credible commitment to the right kind of "exit strategy" should substantially improve the ability of monetary policy to deal with the unusual challenges posed by a binding zero lower bound during a deep financial crisis; and, to the extent that this is true, the development of an integrated framework for policy deliberations, suitable both for crisis periods and for more normal times, is a matter of considerable urgency for the world's central banks. 


\section{REFERENCES}

Auerbach, Alan J. and Obstfeld, Maurice. "The Case for Open-Market Purchases in a Liquidity Trap.” American Economic Review, March 2005, 95(10), pp. 110-37.

Benigno, Pierpaolo and Woodford, Michael. "Inflation Stabilization and Welfare: The Case of a Distorted Steady State.” Journal of the European Economic Association, December 2005, 3(6), pp. 1185-236.

Bernanke, Ben S. "The Crisis and the Policy Response.” Stamp Lecture, London School of Economics, January 13, 2009; www.federalreserve.gov/newsevents/speech/bernanke20090113a.htm.

Christiano, Lawrence J.; Motto, Roberto and Rostagno, Massimo. "Financial Factors in Business Cycles." Unpublished manuscript, Northwestern University, November 2007.

Clarida, Richard H.; Gali, Jordi and Gertler, Mark. "The Science of Monetary Policy: A New Keynesian Perspective." Journal of Economic Literature, December 1999, 37(4), pp. 1661-707.

Cúrdia, Vasco and Woodford, Michael. "Credit Frictions and Optimal Monetary Policy.” Unpublished manuscript, Federal Reserve Bank of New York, July 2009a.

Cúrdia, Vasco and Woodford, Michael. "Credit Spreads and Monetary Policy.” NBER Working Paper 15289, National Bureau of Economic Research, August 2009b; www.nber.org/papers/w15289.pdf.

Cúrdia, Vasco and Woodford, Michael. "The Central-Bank Balance Sheet as an Instrument of Monetary Policy." Unpublished manuscript, Federal Reserve Bank of New York, April 2010.

Eggertsson, Gauti B. and Woodford, Michael. "The Zero Bound on Interest Rates and Optimal Monetary Policy.” Brookings Papers on Economic Activity, 2003, 1(34), pp. 139-211.

Faia, Ester and Monacelli,Tommaso. "Optimal Interest Rate Rules, Asset Prices, and Credit Frictions.” Journal of Economic Dynamics and Control, October 2007, 31(10), pp. 3228-54.

Friedman, Milton. “The Optimum Quantity of Money,” in Milton Friedman, ed., The Optimum Quantity of Money and Other Essays. Chicago: Aldine, 1969, pp. 1-50.

Gerali, Andrea; Neri, Stefano; Sessa, Luca and Signoretti, Federico M. "Credit and Banking in a DSGE Model." Unpublished manuscript, Bank of Italy, June 2008.

Gertler, Mark and Karadi, Peter. “A Model of Unconventional Monetary Policy.” Unpublished manuscript, New York University, April 2009.

Goodfriend, Marvin. "Interest on Reserves and Monetary Policy.” Federal Reserve Bank of New York Economic Policy Review, May 2002, 8(1), pp. 77-84; www.newyorkfed.org/research/epr/02v08n1/0205good.pdf.

Goodfriend, Marvin, "Central Banking in the Credit Turmoil: An Assessment of Federal Reserve Practice.” Unpublished manuscript, Carnegie-Mellon University, May 2009.

Goodfriend, Marvin and King, Robert G. "The New Neoclassical Synthesis and the Role of Monetary Policy," in B. Bernanke and J. Rotemberg, eds., NBER Macroeconomics Annual 1997. Volume 12. Cambridge, MA: MIT Press, 1997, pp. 231-96.

Greenspan, Alan. "Performance of the U.S. Economy." Testimony before the Committee on the Budget, U.S. Senate, January 21, 1997.

Hall, Robert E. “Monetary Strategy with an Elastic Price Standard,” in Price Stability and Public Policy. Federal Reserve Bank of Kansas City, 1984; www.kansascityfed.org/publicat/sympos/1984/S84HALL.PDF.

Mehra, Rajnish; Piguillem, Facundo and Prescott, Edward C. "Intermediated Quantities and Returns.” Research Department Staff Report 405, Federal Reserve Bank of Minneapolis, August 2008 version; www.minneapolisfed.org/publications papers/pub display.cfm?id=1115. 


\section{Cúrdia and Woodford}

Mishkin, Frederic S. "Monetary Policy Flexibility, Risk Management and Financial Disruptions." Speech at the Federal Reserve Bank of New York, January 11, 2008; www.federalreserve.gov/newsevents/speech/mishkin20080111a.htm.

Reis, Ricardo. "Interpreting the Unconventional U.S. Monetary Policy of 2007-09.” Unpublished Manuscript, Columbia University, August 2009.

Rotemberg, Julio J. and Woodford, Michael. "An Optimization-Based Econometric Framework for the Evaluation of Monetary Policy,” in B. Bernanke and J. Rotemberg, eds., NBER Macroeconomics Annual 1997. Volume 12. Cambridge, MA: MIT Press, 1997, pp. 297-346.

Summers, Lawrence. "How Should Long-Term Monetary Policy Be Determined? ” Journal of Money, Credit, and Banking, August 1991, 23(3 Part 2), pp. 625-31.

Svensson, Lars E.O. "Inflation Forecast Targeting: Implementing and Monitoring Inflation Targeting." European Economic Review, June 1997, 41(6), pp. 1111-46.

Svensson, Lars E.O. "Monetary Policy with Judgment: Forecast Targeting." International Journal of Central Banking, May 2005, 1(1), pp. 1-54.

Svensson, Lars E.O. and Woodford, Michael. "Implementing Optimal Policy through Inflation-Forecast Targeting," in B.S. Bernanke and M. Woodford, eds., The Inflation Targeting Debate. Chicago: University of Chicago Press, 2005, pp. 19-92.

Taylor, John B. "Discretion versus Policy Rules in Practice.” Carnegie-Rochester Conference Series on Public Policy, December 1993, 39(1), pp. 195-214.

Taylor, John B. "Monetary Policy and the State of the Economy." Testimony before the Committee on Financial Services, U.S. House of Representatives, February 26, 2008.

van Rixtel, Adrian. “The Exit from Quantitative Easing (QE): The Japanese Experience.” Prepared for the Symposium on Building the Financial System of the 21st Century: An Agenda for Japan and the United States, Harvard Law School, October 2009.

Woodford, Michael. Interest and Prices: Foundations of a Theory of Monetary Policy. Princeton, NJ: Princeton University Press, 2003.

Woodford, Michael. "Forecast Targeting as a Monetary Policy Strategy: Policy Rules in Practice.” NBER Working Paper 13716, National Bureau of Economic Research, December 2007; http://www.nber.org/papers/w13716.pdf.

Woodford, Michael. "Optimal Monetary Stabilization Policy.” Unpublished manuscript, Columbia University, September 2009. 